\title{
La datificación como propuesta de análisis. El caso de la Revista de Historia de América, 1938-1948
}

\author{
Alexandra Cristina Pita González* \\ Maria del Carmen Grillo** \\ Fernando Morales***
}

Recibido el 30 de abril de 2020; aceptado el 5 de junio de 2020

\section{RESUMEN}

La Revista de Historia de América comenzó a publicarse en 1938, gracias a la iniciativa y el tesón del historiador mexicano Silvio Zavala, y al apoyo del Instituto Panamericano de Geografía e Historia. Este artículo es parte de un proyecto mayor de investigación que analiza los diez primeros años de la revista. Pretende ser un aporte a los estudios de las revistas culturales desde una perspectiva metodológica que abra nuevas formas de entender este objeto de estudio. Su principal aportación radica en exponer la manera como se analizó una publicación y las redes intelectuales que la hicieron posible mediante la datificación, término con el cual nos referimos a la manera en que se construyó el andamiaje relacional de los datos significativos, para su recombinación e integración posterior.

Palabras clave: Revista de Historia de América, redes, datificación, métodos cuantitativos.

* Universidad de Colima, Colima, México. Correo electrónico: apita@ucol.com.mx. ORCID: https://orcid.org/0000-0003-1211-0365.

** Universidad Austral, Buenos Aires, Argentina. Correo electrónico: mgrillo@austral.edu.ar. ORCID: https://orcid.org/0000-0001-5501-2904.

*** Universidad de Colima, Colima, México. Correo electrónico: fermorales@gmail.com. 


\title{
The datification as a proposal for analysis. The case of the Revista de Historia de América, 1938-1948
}

\begin{abstract}
The Revista de Historia de América began publication in 1938, thanks to the initiative and tesson of the Mexican historian Silvio Zavala, and the support of the Pan American Institute of Geography and History. This article is part of a major research project that analyzes the first ten years of the journal. It aims to be a contribution to the studies of cultural journals from a methodological perspective that opens up new ways of understanding this object of study. Its main contribution lies in exposing the way in which a publication was analyzed and the intellectual networks that made it possible through datification, a term by which we refer to the way in which relational scaffolding of significant data was built, for recombination and subsequent integration.

Key words: Revista de Historia de América, networks, datification, quantitive methods.
\end{abstract}

\section{INTRODUCCIÓN}

Como sintetiza Annick Louis al hacer un breve repaso por el estado del arte en el estudio de las revistas literarias, para la década de 1990 existían dos tendencias analíticas dominantes, las cuales, pese a sus diferencias, compartían la manera como concebían las publicaciones al considerarlas como "un espacio común de exposición de tendencias estéticas e ideológicas, y no como agentes culturales activos”. Alejarse de ambos sentidos significa considerarlas "no como un espacio donde se refleja la vida intelectual, sino donde ésta se gesta”. Esto significa, según Louis, que para convertir una revista en un objeto autónomo se requiere definir una aproximación metodológica que parta de presupuestos epistemológicos:

el concepto de objeto autónomo es un postulado epistemológico que implica que la revista no se estudia en función de un autor, de una ideología, de una época, sino en tanto objeto simbólico productor de relaciones e ideología, y no significa en ningún caso aislar las revistas de sus contextos de producción. Por otra parte, interesarse en revistas o publicaciones periódicas porque éstas fueron dirigidas por algún escritor que uno estudia, o porque un escritor célebre participó en ellas, no impide considerarlas un objeto autónomo. ${ }^{1}$

1 Según Annick Louis, "Las razones por las cuales estudiamos una revista no determinan necesariamente la metodología utilizada ni los presupuestos metodológicos”. Louis, “Leer una revista literaria”, p. 27-29. 
En este sentido, el presente trabajo propone, más bien, una mirada metodológica al centrarse no en la información de una revista en particular, sino a partir de la forma como se abordó su estudio. A este proceso metodológico lo hemos denominado datificación, con base en la manera como se construyó el andamiaje relacional de los datos significativos, para su recombinación e integración posterior. ${ }^{2}$

Esta reflexión se realiza sobre una publicación específica, o mejor dicho, sobre el proceso seguido para estudiarla. Para explicar por qué se tomó esta decisión es necesario presentar brevemente la publicación y el punto de arranque de su estudio. La Revista de Historia de América (en adelante $R H A$ ), comenzó a publicarse en 1938, gracias a la iniciativa y el tesón del historiador mexicano Silvio Zavala, la colaboración de numerosos historiadores y al apoyo del Instituto Panamericano de Geografía e Historia. La publicación (que se ha mantenido hasta la actualidad), ${ }^{3}$ es un referente importante para la historiografía americana porque en ella se publicaron los trabajos de los historiadores más reconocidos del continente. Además, durante su primera década de vida fue parte de un proceso de profesionalización e institucionalización de la historia en México. ${ }^{4}$

Su estudio comenzó entonces por la elaboración de un proyecto de investigación que excedió por mucho nuestras expectativas iniciales. ${ }^{5}$ Lo que al inicio pareció un recorte significativo de los diez primeros años, suficiente como para dar cuenta de sus orígenes y trayectoria, quedó desbordado por una ingente cantidad de información que conformaba un universo de datos mayor al estimado inicialmente. Intuíamos que la mejor estrategia para entender el universo de los datos visualizados en la revista era desde una perspectiva de la teoría de redes, lo cual nos remitía a otro tipo de preguntas (y, por lo tanto, otro tipo de instrumentos para observarlos). Esta mirada relacional requirió sumar otras fuentes de archivos personales de los principales actores involucrados. Sumamos así la correspondencia, informes y cuentas de su editor, Silvio Zavala y de uno de sus colaboradores asiduos, Rafael

2 Se amplía este concepto en extenso más adelante.

3 La RHA suma 160 números de manera continua, aunque con diferentes regularidades en su aparición.

4 Cfr. Mora Muro, “Silvio Zavala y la institucionalización/profesionalización de la historia en México, 1933-1950”, p. 58.

5 Este artículo es producto de una investigación financiada por la Comisión de Historia del Instituto Panamericano de Geografía e Historia (IPGH) Programa de Asistencia Técnica, 2019 (PAT 2019), al cual agradecemos la oportunidad de desarrollarlo. 
Heliodoro Valle, que resguarda el fondo. ${ }^{6}$ La cantidad de documentos aumentó de manera tan desmesurada, que sólo el pensar en la manera de clasificarla se convirtió en un desafío. Invertimos tiempo en pensar, discutir, decidir y poner a prueba múltiples formas de abordaje, hasta llegar a una forma definitiva a través de una aproximación sucesiva de aciertos y errores. En ese momento pudimos iniciar y releer nuestra revista como un objeto de estudio en su complejidad.

El resultado de esto nos permitió avanzar en dos sentidos. Uno, el de la historia de la revista, que se materializará en una obra de mayor extensión para dar cuenta de sus características y trayectoria, agrupando todas las variables en tres grandes dimensiones explicativas: material (cuestiones técnicas y formales) humana (sobre quiénes componían el universo de la revista), e inmaterial (de contenido). Otro, en el que se enfoca este artículo, conforma el laboratorio de ideas y decisiones de la investigación misma.

Esta preocupación por observar al investigador en su labor, y exponer los caminos seguidos surgió hace tiempo en un trabajo precedente, en el que, a través de la experiencia en analizar revistas culturales, se identificaron las categorías y variables que pueden ser tenidas en cuenta en un análisis sistemático. En aquel trabajo partimos de la premisa de que esas unidades mínimas permiten identificar un objeto textual heterogéneo. Analizar la revista globalmente, como si se tratara de un solo texto homogéneo, impide dar cuenta de su pluralidad y riqueza, de la posibilidad de tensiones o disensos, ni registra los grados o matices, ni las habituales transformaciones temporales que experimentan. A diferencia de otras textualidades, basadas en la unidad y singularidad (un autor, un género), las publicaciones periódicas son en su mayoría objetos heteróclitos, complejos, en términos de autoría (un equipo editorial, diversos colaboradores), en diversidad genérica (en secciones y clases textuales como artículos, reseñas, notas, etcétera), en contenidos y materialidad. El análisis de una publicación debe ser multidimensional mediante descripciones densas, dinámicas y no lineales, es decir, no necesariamente discursivas, sino del tipo de tablas e imágenes elaboradas a partir de ellas. ${ }^{7}$ Mediante la elaboración de grafos de red y otras formas de representación visual, puede verse cómo estos datos, tratados en bases y hojas de cálculo y convertidos posteriormente en representaciones visuales, represen-

6 El primer acervo está resguardado en la Biblioteca del Museo Nacional de Antropología e Historia, y el segundo, en la Hemeroteca Nacional, ambos en la Ciudad de México.

7 Sobre linealidad y tabularidad en el estudio de revistas, véase a Grillo en "Una red en el tiempo. El caso de La Campana de Palo, 1925-1927”, pp. 136-137. 
tan unidades de información que dan cuenta de los aspectos inmateriales o de contenido, técnicos o materiales y humanos. ${ }^{8}$

Con ello esperamos abrir un diálogo intra e interdisciplinar. Por una parte, con aquellos investigadores especializados en los datos, quienes nos recuerdan, aunque parezca una obviedad, pero no lo es, que es necesario problematizar la existencia del dato, como una unidad construida, capaz de integrarse en un proceso que da orden y sentido. ${ }^{9}$ Asimismo, con aquéllos que desde las ciencias humanas reflexionan sobre la necesidad, el beneficio y el impacto que tiene el uso de métodos cuantitativos en nuestros objetos y sujetos de estudio, quienes rechazan los estereotipos que separan a las ciencias sociales de las humanas por el uso de un método sobre otro.

Como afirman en las primeras frases de su introducción Lemercier y Zalc:

acudimos a los métodos cuantitativos no por una convicción ideológica sino por una necesidad: nuestras fuentes nos guiaron a ellos, y nuestros argumentos se basaron en ellos. Para nosotros, cuantificación no es un fin en sí mismo, pero es una herramienta útil y a veces necesaria. ${ }^{10}$

Sin embargo, esta necesidad no se limita a poner cuadros y tablas en una investigación; replantea la división (sustentada en prejuicios) de que las ciencias sociales se basan en números, mientras las humanidades son "irreductiblemente cualitativas". Consideran, por tanto, que debe romperse con la "aislación disciplinar" y la "compartimentación de la investigación".

Asimismo, esperamos dialogar con investigadores que han explorado las cuestiones metodológicas en el estudio de las revistas. Annick Louis planteó, en el estudio previo mencionado, y en uno posterior en el que retomó el tema, dos conceptos como base para su propuesta metodológica. ${ }^{11}$ El primero de esos conceptos es la distinción entre lectura intensiva y exhaustiva; esto es, que para estudiar una publicación hay que leerla teniendo en cuenta las condiciones actuales desde donde se lee, así como las de la época, porque ambas tienen un impacto en el objeto. En ese sentido, la lectura realizada hoy sobre la RHA ha sido lectura de sus contenidos, a la manera tradicional

8 Sobre las dimensiones para abordar una revista, véase a Pita y Grillo en "Una propuesta de análisis para el estudio de revistas culturales”. Sobre el tema de redes, véase también a Rodríguez, "Cómo utilizar el Análisis de Redes Sociales para temas de historia”.

9 Sobre la construcción conceptual del dato, véase a Prada, "Epistemología del dato", pp. 307-334.

10 Lemercier y Zalc, Quantitative Methods, pp. 1-2.

11 Louis piensa el análisis de las publicaciones a partir de estos contextos y plantea una serie de ejemplos. Louis, "Las revistas literarias como objeto de estudio”. 
(como en papel, pero en pantalla), lineal e intensiva, y ha sido lectura extensiva, discontinua, de sus unidades discretas. ${ }^{12}$

El segundo concepto de Louis es el de contexto: entendido de modo plural, hay contextos de publicación, de edición, de producción y de lectura. Con respecto a los contextos de publicación, de edición y de lectura, la revista tiene un marcado tono institucional, correlativo del proyecto de Silvio Zavala: es una publicación del IPGH, es una revista académica, y busca realizar un recorrido entre instituciones e historiadores. El contexto de producción ("las condiciones materiales específicas, culturales y sociales, de producción de los textos") ${ }^{13}$ se intenta recuperar por vía de los documentos personales de Silvio Zavala y de Rafael Heliodoro Valle, que dan cuenta de las relaciones entre la revista y los autores (gestión de reseñas, de artículos, de fichas bibliohemerográficas, por ejemplo). De este modo, se buscó integrar estas nociones complejas de lectura y contexto.

Por su parte, Verónica Delgado, tras mostrar la pertinencia de la perspectiva de Raymond Williams al enfatizar que las publicaciones son formaciones o relaciones entre grupos, por lo que debe observarse su estudio interno y externo, enlista varios aspectos que deberían ser tomados en cuenta a la hora de analizar una revista. Propone estudiar las estrategias de enunciación y políticas tipográficas; el conjunto de prácticas de quienes hacen la publicación (formas de sociabilidad) la constitución del grupo (señalando su grado de especialización que dan a la publicación); las modificaciones, desplazamientos y cambios en el tiempo; los aspectos materiales e ideológicos; la manera en que polemiza; y por último, propone prestar atención a la problemática del archivo. ${ }^{14}$

Otra manera de plantear un acercamiento metodológico es la de Hanno Ehrilcher, quien, al preguntarse por el impacto del estudio de las revistas en la era digital, relaciona este campo de investigación con el de las humanidades digitales, que busca un cambio en las metodologías y prácticas de las tradiciones disciplinares. En este sentido y tras un balance de los proyectos realizados en este campo, presenta su "propuesta pragmática”: reunir un corpus de textos digitalizados y crear nuevas herramientas para realizar un análisis comparativo de los textos. Para ello es necesario realizar búsquedas automatizadas y relaciones de metadatos diseñados específicamente para el

12 Hay, sin embargo, una diferencia. Louis adjudica la lectura extensiva del lector contemporáneo a la lectura sometida a la periodicidad o frecuencia, y a la lectura fragmentada, según interés. En nuestro caso, el concepto de lectura extensiva se aplica a la detección de unidades de información segmentables.

13 Louis, "Las revistas literarias como objeto de estudio".

14 Delgado, "Algunas cuestiones críticas y metodológicas en relación con el estudio de revistas”, pp. 18, 20-23. 
análisis de revistas. ${ }^{15} \mathrm{El}$ presente trabajo es una presentación de ese intento: a partir de un corpus ya digitalizado y presente en bases de datos académicas, generar una base propia, con otros descriptores, para realizar una lectura no secuencial de su contenido.

Por último, cabe mencionar el orden que seguimos en el desarrollo. Iniciamos con un señalamiento de cómo se procesó la información que nos remite a los aspectos materiales de la revista. Nuevamente aclaramos que, aunque se haga referencia a algunas de sus características, éstas no son el objeto del presente artículo (no es una versión reducida del libro), sino sólo en función de la mirada metodológica. Continuamos con la forma como fueron tratados los aspectos inmateriales, que abarca la dimensión humana y sus redes. Para comprender este apartado es necesario iniciar con la explicación de lo que fue el proceso de datificación, para posteriormente, dar a manera de ejemplos, algunos resultados de las visualizaciones realizadas.

\section{LOS ASPECTOS MATERIALES}

El estudio de la publicación se inició con unos datos básicos y necesarios, como son lugar de edición, formato, cantidad de páginas y diseño de portada, impresión, papel y encuadernación, cantidad de números, periodicidad, precio, tirada y zona de distribución. Parte de esta información se obtiene de la revista misma y puede sistematizarse con catálogos en línea, que tienen ya registrados mayores detalles de cada número. ${ }^{16}$

15 Existen dos tendencias, la que utiliza la tecnología como forma de proyectar, pero mantiene su manera de interpretar "textos o artefactos culturales”, y la que busca romper con esta continuidad de la tecnología al servicio de la tradición. Dentro de esta última existen también tendencias: está la de los "utópicos de la cibercultura” que buscan recrear los valores humanísticos a través de la colaboración que implica las humanidades digitales, y también una visión menos radical, que "considera la tecnología el medio ideal para liberar definitivamente las humanidades de unas limitaciones metodológicas como serían, desde esta perspectiva, la fijación en la interpretación hermenéutica y la lectura intensiva de textos canónicos seleccionados”. El mejor exponente es el Laboratorio The Literary Lab de la Universidad de Stanford, coordinado por Franco Moretti, quien realiza un análisis “estadístico-cuantitativo de datos de gran cantidad a base de automatismo algorítmicos” Ehrlicher, "El estudio de revistas culturales en la era de las humanidades digitales. Reflexiones metodológicas para un debate”, pp. 30-32, 35-36. Sobre este proceso de digitalización realizado por bibliotecas y archivos es necesario tener en cuenta retos tecnológicos y académicos. Para ver un estudio remitimos a Rißler-Pipka, "Sobre los problemas de investigación con revistas culturales digitalizadas del mundo hispanohablante”.

16 La revista ha sido digitalizada por JStor; sin embargo, como el acceso a este repositorio requiere un pago, también se digitalizó por un acuerdo entre el IPGH y el INHA en otra plataforma. Este proceso no está concluido, sólo existen los números tal cual. Además, en la página web de la revista se pueden consultar los números de 1938-1948. 
A partir de la lectura de sus portadas y sumarios se observan también cambios, como la composición del equipo de editores, el consejo directivo, las secciones, y el cambio de periodicidad. Lejos de ser una simple enumeración de datos, el observar esta información permite problematizar y buscar respuestas no sólo en las páginas de la publicación, sino en otra documentación (cartas, informes, notas).

Iniciamos con lo que a simple vista aparece como el dato más sencillo: el lugar de edición. La $R H A$ se fundó en la ciudad de México, porque era ahí donde tenía sede el Instituto Panamericano de Geografía e Historia desde su creación en 1929 (hasta la actualidad). Que el IPGH sea una institución continental con sede en México remite a la geopolítica de las relaciones interamericanas de la primera mitad del siglo Xx. Por ello, no es casual que México haya fungido como una bisagra para articular las relaciones entre Estados Unidos y América Latina, como tampoco lo fue el que la fundación del Instituto se hubiera dado en la álgida conferencia panamericana reunida en La Habana en 1928.

Tomando en cuenta este marco general, en el que primaba el denso entramado de la política internacional, la línea editorial de la publicación fue panamericanista. Esto se tradujo en una búsqueda incesante por incluir en el consejo editorial a representantes de casi todos los países y, en sus páginas, a un número siempre creciente de colaboradores extranjeros. Con ello se pretendía representar -a pequeña escala-, el deseo institucional de acercar a través de proyectos disciplinares a los países del continente. Esto quedó claro desde el primer número, cuando se enunciaron los propósitos de la publicación.

En 1947, tras la creación de la Comisión de Historia en el IPGH, la publicación se institucionalizó más aún. Por ello no es extraño encontrar que, en lugar de escribir nuevos propósitos, se transcribiera la resolución de la primera reunión de consulta de la comisión. Esto se convirtió en una constante en los siguientes números, que daban cuenta de las actividades del IPGH y sus comisiones, especialmente la de Historia (actas, estatutos, resúmenes, proyectos). Así, la revista se presentaba como el espacio académico que perfeccionaba el aspecto institucional al integrar a los historiadores de toda América con la información de lo que podríamos llamar los datos duros (programas, fechas, asistentes), pero también con una visión fundacional del trabajo mancomunado: elaboración de guías y catálogos de historiadores y centros de investigación.

Este perfil académico, sobrio, se puede observar también en otros aspectos materiales como la portada, el formato, la cantidad de páginas, la periodicidad, el precio de venta y el tiraje. Al ser una publicación institucional, de historiadores (que buscaban identificarse con la ciencia y no con las artes), las tapas son simples: en un papel tipo cartulina de color tenue se colocan el 
nombre del Instituto, el título, se aclara que es trimestral (al menos al principio), el número, la ciudad, mes y año. En la contratapa se colocan el sumario y los datos de la publicación: dirección (la sede del IPGH) y el del equipo editorial.

$\mathrm{Su}$ formato es el de una revista libro (con numeración corrida desde 1944), pequeña en sus dimensiones (17,5 por 26 centímetros), voluminosa en cantidad de páginas (que rondó entre 200 y 250, con mínimos de 160 aproximadamente en el primer año, y picos de 400-500 en tres números). Publicó cuatro números el primer año (enero-marzo, abril-junio, julioseptiembre y octubre-diciembre); tres números entre 1939 y 1942 (eneroabril, mayo-agosto, septiembre-diciembre); en 1943, publicó sólo un número por la Segunda Guerra Mundial, ${ }^{17}$ y en 1944 adquirió un ritmo regular de dos números anuales (enero-junio, julio-diciembre).

La revista se ofrecía en canje a otras publicaciones y se repartía de manera gratuita a historiadores reconocidos o instancias estrechamente vinculadas (universidades, institutos, archivos, bibliotecas); en la contraportada se registra que el precio estimado era de cuatro dólares, pero para el envío a personas en particular fueron importantes los contactos personales de los miembros del equipo y los representantes del consejo directivo, éstos mencionaban quiénes debían recibirla o sugerían a algunas personas que lo solicitaran por escrito. Para 1943, se restringió el tiraje de la publicación, por lo que no se incorporaban nuevos suscriptores, salvo algunas excepciones, y para 1948, el IPGH decidió que sólo se distribuiría de manera gratuita a sus colaboradores (con al menos un trabajo para cualquiera de las secciones por año) y en canje con otras instituciones científicas. ${ }^{18}$

La sección de Noticias permite conocer el presupuesto que se estimaba para el pago de requerimientos de la revista; casi cerrando la primera década,

17 Una nota advertía ya en diciembre de 1941:

"La situación creada en América, a consecuencia de los recientes acontecimientos internacionales, dificulta el desarrollo normal de los trabajos encomendados al Instituto Panamericano de Geografía e Historia. La Revista de Historia de América se ve obligada, por razones de orden económico, a reducir el número de sus cuadernos anuales. Esperamos publicar dos entregas en el curso de 1942, la primera hacia el mes de junio, y la segunda, en el caso de ser posible, en diciembre. Se procurará que los artículos, reseñas y bibliografía conserven la disposición y el volumen que han venido teniendo en nuestros cuadernos ordinarios".

Los editores, "Aviso a los lectores", Revista de Historia de América 4, 13 (diciembre de 1941), retiración de tapa. Sin embargo, en retiración de portada publicaron, como era habitual, la frecuencia anterior (abril, agosto y diciembre). Los editores. "Aviso a los lectores". Revista de Historia de América, 4, 11 (diciembre de 1941), 13.

18 HN-FHV, serie IPGH, carta de Rafael Heliodoro Valle a Pedro Sánchez, 4 de junio de 1944 y HN-FHV, serie Comisión Historia, carta de Javier Malagón a Rafael Heliodoro Valle, 2 de febrero de 1949. 
en 1948, era de 30000 pesos mexicanos anuales. ${ }^{19}$ Nada menciona la publicación sobre el tiraje. Para encontrar esta información fue preciso complementar la búsqueda en otros archivos, donde a través de la correspondencia entre los miembros del equipo editorial se puede saber que el tiraje fue de 1500 ejemplares desde 1939 cuando la revista pasó de ser cuatrimestral a trimestral. ${ }^{20}$

Ahora bien, dentro de esta dimensión material identificamos también aspectos que tienen que ver con el formato y con el contenido, como el título, programas y notas editoriales, índices, secciones y distribuciones de páginas, temas y problemas sobre los que la revista se expide, como un programa continental para la docencia y la investigación en historia, la preocupación bibliográfica, la temática de archivos y catálogos, que recorre todas las secciones; así como la ornamentación, los avisos y las novedades.

Al pretender ser una revista académica, el título de la publicación se limitó a describir el espacio (América) y el campo (la historia). Sin embargo, en conjunto, la Historia de América tenía implícita la búsqueda por construir una especialidad que fuera incluyente de todos los países y que pudiera ser estudiada por todos los investigadores (americanos o europeos). Si se hubiera llamado hispano, latino o iberoamericana habría excluido a los Estados Unidos. Si se hubiera designado panamericana, no sólo habría sido criticada por intelectuales que veían con desconfianza el movimiento panamericano, sino que además habría mostrado un excesivo perfil institucional, con pérdida de autonomía. Cabe mencionar que fueron absolutamente conscientes de las implicancias de estas sutilezas del lenguaje. Cuando Silvio Zavala y Lewis Hanke visitaron al ingeniero Pedro Sánchez, presidente del IPGH en 1937 para presentarle el proyecto y pedir su apoyo, se aclaró que la revista estaría dedicada a la historia de América. ${ }^{21}$

19 La Comisión de Historia del IPGH, en 1948, estimaba, con una frecuencia de dos números anuales, una partida presupuestada de 30000 pesos, que se desglosaba en los números (20 000), un índice anual (3 000) y el pago de colaboraciones (7 000). Zavala y el equipo editorial cobraban igual que cualquier otro autor por cada página que publicaran en la Revista a razón de 3 pesos mexicanos la hoja. Como ellos escribían casi toda la sección de bibliografía y las reseñas, percibían las retribuciones más altas como autores.

20 El IPGH decidió que por motivos presupuestales la revista debería de salir sólo tres números al año (no cuatro, como fue el primer año). A cambio, se comprometieron a que se aumentara el tiraje. BNAM-FSZ, serie IPGH, caja 1, exp. 1, fol. SZ8676. Carta de Pedro Sánchez a Silvio Zavala, 29 de marzo de 1939.

21 Hanke recordó años después que se había encontrado con Zavala en la ciudad de México en 1937 cuando iba de camino a realizar una estancia de investigación en Guatemala. En ese paso por la ciudad, Zavala le presentó a Alfonso Reyes y a Genaro Estrada, y le pidió que lo acompañara a hablar con el ingeniero Pedro Sánchez en el Instituto para convencerlo de fundar una revista dedicada al estudio de la historia de América. Sánchez se mostró reticente pues no confiaba en los historiadores (a quienes consideraba “tercos y pendencieros”), pero 
Por esto no es extraño que, desde el primer número, se enuncia el programa en su presentación titulada "Los propósitos", en la que los editores manifiestan una necesidad: la de elaborar las historias nacionales afirmados en una perspectiva continental, con relaciones con Estados Unidos de Norteamérica y Brasil, pero con "la fuerza unificadora de España”. ${ }^{22}$ Esto es más que una visión temática y de alcance: es, especialmente, una cuestión de método, una conciencia del trabajo del historiador científico y de su potencia al integrarse en una comunidad de otros historiadores con la misma vocación, en congresos, comisiones de pares, edición de libros, cátedras, etcétera.

En este sentido, la RHA es fundante: literalmente, sienta los cimientos de un modo de trabajar que se declara en sus contenidos, en los artículos, reseñas, noticias y notas necrológicas, y que puede observarse en las revistas y libros mencionados: se trata de la importancia de trabajar científicamente sobre el documento. Si bien en cada número se publica un promedio de tres artículos (de aproximadamente treinta páginas cada uno), la mayor extensión en páginas se dedica a reseñas, revistas y bibliografía.

El conjunto compone, más allá de la temática (especialmente, la historia colonial), un vasto metatexto historiográfico, bibliográfico y archivístico. ${ }^{23}$ El programa editorial produce tanto un conjunto de contenido metatextual (qué es la historia, cuál es su objeto, quién hace historia, cómo debe hacerse, cuáles son sus disciplinas auxiliares, etcétera), cuanto un capital social, con palabras de Bourdieu, entendido como el conjunto de recursos provenientes de la pertenencia a una red con los que cuentan sus miembros. ${ }^{24}$

En ese sentido, todas las secciones son tributarias de su programa inicial y de la misión de servir y formar historiadores. Por ello, nuestro análisis toma cada sección como unidad desde su captura en la base de datos hasta su análisis, de modo que se ha seguido el criterio de organización de las secciones, aun cuando las búsquedas puedan hacerse en cualquier sentido, la uni-

escuchó los argumentos con atención y al año siguiente aprobó su creación. Al enterarse de la decisión, Zavala conformó con rapidez el primer número con sólo tres artículos (uno suyo, otro de Altamira y otro de Hanke), ante el temor de que Sánchez cambiara de opinión. Hanke y Vericat, “Experiencias Con Silvio Zavala, 1933-1949”, p. 603.

22 Los editores, “Los propósitos”, Revista de Historia de América, núm. 1 (marzo de 1938): VVI; citada, p. V.

23 La noción de metatexto orientada a la historia (en particular a la crónica) ha sido desarrollada por Walter Mignolo como los textos en los que se define un dominio de objetos (tema, contenido) y los rasgos críticos de los textos, sus características formales. En este sentido, los artículos, las reseñas, la mención de libros y revistas buscan establecer temas y formas relativas al texto de historia y a la práctica del historiador. Mignolo, "El metatexto historiográfico y la historiografía indiana”.

24 Bourdieu, “Le capital social”, pp. 2-3. 
dad mínima de información remite a su sección correspondiente. Esta decisión reposa en la identidad genérica de cada pieza según su sección.

La primera sección es Artículos, la cual, aunque no fue la más voluminosa en cantidad (se publicó un promedio de tres artículos por número) representa en nuestra interpretación el peso de una tradición, entendiendo por ello la búsqueda por valorar tanto la manera como se venía realizando la historia a partir de los documentos, como la tradición entendida por el lazo que vinculaba a estas excolonias con su historia. Se realizó un registro correspondiente a cada artículo información básica sobre él (año, número, páginas, título, palabras clave, idioma) y sobre su autor (apellido y nombre, nacionalidad, ciudad u otra observación sobre el texto). Esto permitió cuantificar quiénes contribuyeron en esta sección e identificar dos grandes líneas en las que podría agruparse la mayor parte de los artículos: la de la investigación documental y la de un relevamiento relativo a centros de documentación (archivos, hemerotecas, bibliotecas) del continente.

La segunda sección ha sido Reseñas, que fueron numéricamente cuantiosas: a lo largo de los primeros diez años se publicaron 978 reseñas de libros. La mayoría de éstas se escribió en español, y fueron pocas las que se publicaron en inglés y en portugués, más allá de su vocación continental en los tres idiomas. Los campos identificados para cada reseña, además del volumen, el número y el intervalo de páginas, han sido las autorías ${ }^{25}$ (de los libros y de las reseñas), títulos de los libros, ciudad de edición, fecha, editorial, idiomas (de la reseña y del libro), procedencia de la reseña (ciudad e institución, siempre que estuviera indicada). Además, se generaron entre tres y cinco palabras clave por obra reseñada (dos para tema, ubicación geográfica e intervalo temporal que menciona el título del libro).

Algunos resultados inmediatos permiten ver el enorme peso de México en la autoría de reseñas (más de la mitad), a la que siguen la ciudad de Buenos Aires, Argentina, y varias ciudades de Estados Unidos. Por debajo de estos países siguen Cuba, República Dominicana y otros países latinoamericanos. Las visualizaciones son mapas que indican la procedencia de reseñas por ciudades, mapas con las ciudades en las que se habían editado los libros y gráficos cuantitativos por autor/institución (en los casos en que se menciona).

25 Sobre el tema de la autoría por ejemplo, una nueva forma (con la cual coincidimos) para pensar la noción de autoría es la que propone Annick Louis al examinar de nueva cuenta la relación entre autoría personal y colectiva o colaborativa. Ella postula que de alguna manera "la autoría en una revista siempre es colectiva” porque para la publicación de cada número es necesaria la participación de numerosos actores. Pensar que lo colectivo no es sólo una suma de actores sino "un efecto nuevo" porque una revista genera un espacio compartido. Por ello, prefiere hablar de grados de autoría. Louis, “Leer una revista literaria”, p. 44. 
Otro resultado significativo, en relación con las autorías, es el volumen de publicación por persona: un escaso número de colaboradores publicó gran cantidad de reseñas, mientras que un gran número colaboró con escasa cantidad. Al principio, los reseñistas eran los mismos autores de artículos y miembros del equipo editorial. Con el paso del tiempo, publicaron reseñas historiadores formados en El Colegio de México y en otras instituciones, lo que muestra el papel orientador de la revista.

Interpretamos que la función de estas reseñas fue la de conformar la biblioteca del historiador, idea que se continúa con la sección bibliográfica (libros y revistas). Esta sección fue estratégica para la publicación porque reforzaba su orientación a la archivística, la bibliotecología y la catalogación.

En estrecha relación con la sección de Reseñas están las secciones Revistas (hasta el número 10) y Bibliografía (que integraría a las revistas a partir del 11). El peso de la sección de Bibliografía se vislumbró desde el inicio por su extensión (aproximadamente 100 páginas por número), lo cual motivó que no se registrara en la base de datos, sino que se utilizara otro tipo de estrategia para poder extraer la información de casi 16 mil unidades de contenido. Dado el enorme volumen de información, se han elaborado varias representaciones visuales que muestran el mundo editorial de libros y revistas que se comentaba, consignando por ciudad, autores y contribuciones en la bibliografía. Además, dada la importancia de la sección para la profesionalización, numerosas cartas entre los participantes, pertenecientes a los archivos estudiados, permiten recuperar la compleja trama de acuerdos entre los principales coordinadores de la sección: Silvio Zavala, Rafael Heliodoro Valle, José Torre Revello e Ignacio Rubio Mañé. A partir de esta documentación, se pudo determinar la manera como se fue construyendo esta red.

La revista también incluyó una sección dedicada a Notas Necrológicas, titulada del mismo modo. Es una sección pequeña, pero significativa, porque permitió explicar los sentidos de pertenencia de la red. Partimos de la premisa de que las notas necrológicas publicadas en la RHA fueron parte de una estrategia general de formar la historia como disciplina. Al notificar a sus lectores la muerte de historiadores destacados enfatizaba la formación académica institucional y el valor del ejercicio profesional. Para desarrollar esto se tomaron dos caminos: el análisis del contenido de las notas, destacando los detalles estilísticos, el tono, la cercanía entre fallecido y autor de la nota, así como las personas, instituciones y revistas que le sirvieron de referentes. A esto se agrega el análisis de grafos de red, tomando sus herramientas para entender los vínculos entre fallecidos y autores y el peso de determinadas instituciones académicas.

Por su parte, la sección Noticias, que comenzó en el número 19, permitió entender el apego institucional de la revista. Si bien hay noticias de tipo 
académico, predominan documentos informativos de tipo protocolar, especialmente después de la creación de la Comisión de Historia. Las noticias y los documentos publicados muestran la energía en el desarrollo de equipos y planes de trabajo, el despliegue continental y la visión de la necesidad de formación del historiador profesional; no sólo se trata de informar sobre lo que están haciendo los historiadores, sino de promover que se incorporaran a la red y que, una vez en ella, participaran nuevas actividades. Dada la gran cantidad de información en esta sección, los gráficos muestran y describen el peso de instituciones y personas mencionadas en las noticias, así como el tipo de noticias.

Ya para el final del decenio, en la Recapitulación de junio de 1948, Silvio Zavala se enorgullece del crecimiento y la estabilización de los contenidos de la revista:

A medida que la experiencia lo ha aconsejado, se han introducido algunos cambios en el contenido de las secciones y en la disposición tipográfica de la revista; por ejemplo, el que se advierte a partir del número once con respecto a una nueva sistematización de la bibliografía. Es claro que la posibilidad de efectuar mejoras queda siempre abierta, pero al cabo de una década ya se ha logrado cierta estabilidad en las secciones de la revista y en la manera de presentarlas. Cada volumen anual cuenta con su respectivo índice analítico. ${ }^{26}$

\section{EL ASPECTO INMATERIAL: LA DIMENSIÓN HUMANAY SUS REDES}

La dimensión humana se ocupa de entender el universo de personas que colaboraron de una u otra manera para la publicación: el director, el equipo editorial, los colaboradores (vivos o muertos, como es el caso de los historiadores que pueblan las notas necrológicas), el comité directivo, la administración y los impresores. Con ello, se puede evidenciar que una publicación no es un producto que surge espontáneamente, sino que es el fruto de un conjunto de relaciones previas que maduran y se vinculan en un emprendimiento cultural como éste. ${ }^{27}$ citada, p. V.

27 Se pueden detectar tres momentos al considerar la aparición de una revista: el primero se presupone que es el primer número, pero esto no da cuenta de la labor desplegada por un grupo de personas antes de esto, es decir, no nos permite entender la conformación de una red previa. Debe pensarse este primer momento como un proceso con etapas en donde según sea el caso de cada revista, tendrá más peso el tiempo que transcurrió antes de su aparición. Distinguir cuándo inicia el segundo momento es una tarea más complicada porque suele asociarse este momento con los cambios estructurales (de formato, de editor, de lugar, de 
Este conjunto de personas, conectadas e interactuando en función de hacer de la revista un producto colectivo, fue significativo al tratarse de un período fundacional porque existió un peso mayor en la definición del perfil de la publicación. Así, entender quiénes la crearon y sostuvieron nos remite a las acciones de un grupo de personas que a través de la revista se posicionaron en el campo intelectual. Como han planteado otros estudiosos de publicaciones, hacer una revista implica definir una postura política, cultural, artística, o en este caso, académica. ${ }^{28} \mathrm{El}$ objetivo de la $R H A$ consistió en conformar un programa para profesionalizar al historiador; esto requirió de prácticas, temas, lecturas, escritura, pero también, más allá de sus roles institucionales, para sus miembros, hacer una revista comporta llevar el día a día: resolver situaciones, establecer contactos, supervisar contenidos, seguir rutinas. ${ }^{29}$

La revista, entendida como espacio de sociabilidad, ${ }^{30}$ consolida unas relaciones de camaradería, discipulado y docencia que habían comenzado con varios de los participantes en España, en el Centro de Estudios Históricos de Madrid y en el Archivo de Indias en Sevilla, y que se proyectarían en La Casa de España/El Colegio de México y el Instituto de Investigaciones Históricas de la UNAM. También sería un medio de vida para varios de sus colaboradores y un lugar para hacer las primeras armas en publicaciones para los jóvenes estudiantes de historia.

De este modo, el análisis de la dimensión humana y sus redes se realizó respetando los fondos documentales, es decir, 26 números de la revista y de los archivos personales de Silvio Zavala y en menor medida, Rafael Heliodoro Valle, que nos permitió entender cuál fue el universo humano que compuso e hizo posible la revista; de qué manera esta composición se configuró como una red intelectual y cuáles fueron sus características (dimensión, relación, influencias); cómo los libros y revistas mencionados permiten entender los circuitos editoriales; de qué manera los artículos, notas y reseñas dan muestras del proceso de especialización de la Historia (sostenida en disciplinas y ciencias auxiliares).

temática). Ahora bien, señalar esta temporalidad significa que, si las redes son previas a las publicaciones, no les dan un carácter autónomo, lo cual significa que su desarrollo depende de los cambios que sufra la revista. Pita, "Las revistas culturales como soportes materiales, prácticas sociales y espacios de sociabilidad”, pp. 236, 238 y Pita, “Introducción”, p. 7.

28 Fernanda Beigel hizo énfasis en el carácter programático de las revistas culturales. Véase a Beigel, Las revistas culturales como documentos de la historia latinoamericana”.

29 Sobre los dos espacios de una revista, el público y el privado, propio de la gestión y la negociación, véase a Pluet-Despatin. "Une contribution a l’histoire des intellectuels: les revues".

30 Pluet-Despatin, "Une contribution a l'histoire des intellectuels: les revues”. 
Ya se ha abordado en estudios precedentes el papel de Zavala en la profesionalización de la historia, ${ }^{31}$ en su rol institucional, ${ }^{32}$ en su proyecto de construcción de una historia continental de América. ${ }^{33}$ En lo que respecta a la $R H A$, es claramente perceptible su posición de centralidad dentro de la red de la revista, por un lado, como su director, y por otro, destaca el volumen de su contribución en artículos y reseñas. En los primeros años, formó equipo con Francisco Monterde García Icazbalceta y con Felipe Teixidor (hasta el número 8); en el número 4, se incorporaría Jorge Ignacio Rubio Mañé, quien contribuiría con gran cantidad de reseñas. Al equipo editor se le sumarían corresponsales por países en un consejo directivo de entre 10 y 16 miembros, con diverso grado de participación. Los más prolíficos fueron José Torre Revello (Argentina) y Rafael Heliodoro Valle (Honduras); también contribuyeron regularmente Bert James Loewenberg (Estados Unidos), Fermín Peraza Sarausa (Cuba), José Miguel Vélez Picasso (Perú); aunque con pocas publicaciones, el rol de Lewis Hanke es clave, pues configura un papel articulador entre las instituciones de Estados Unidos, sus historiadores y la $R H A$.

\section{MATERIALIZANDO LO INTANGIBLE, LA DATIFICACIÓN}

Para hacer un análisis de las redes que se entretejen en la revista fue necesario determinar el material del trabajo y comprenderlo en su totalidad. Un ejercicio clave fue la identificación de unidades, constituidas en datos. Pasar de lo dado al dato consiste en dotar de significación a un fenómeno percibido, y generar un ordenamiento, una formalización. ${ }^{34}$

La datificación comienza mucho antes de siquiera tener en claro cuáles serán los campos por datificar, es un ejercicio que parte de la reflexión acerca de las acciones y decisiones que se tendrán que tomar y ejecutar en torno al corpus documental. No hay una única forma de proceder, ya que es el objeto el que, a partir de la información que nos ofrece, delimita el campo de posibilidades. Cualquier acción mental que lleve a concientizar el proceso de datificación es válida en la medida en que el dato se conforma como unidad con significado y un peso relativo por su ubicación y sus capacidades relacionales en el contexto del conjunto de datos y en la trama de una red. Uno

31 Mora, "Silvio Zavala y la institucionalización/profesionalización de la historia en México, 1933-1950”, pp. 57-89.

32 Fernández, "Silvio Zavala y la historiografía americana: Una vida de vínculos intelectuales”, pp. 33-55.

33 Pani, “Silvio Zavala y la historia de América: Un juego de escalas”, pp. 177-18.

34 Prada, "Epistemología del dato”, pp. 307-334. 
de los objetivos de esta práctica es dotar de sentido y determinar el peso relacional de cada nodo (para el caso de redes, por ejemplo), que en un determinado universo conforma el corpus de datos con los que se trabajará.

El dato, que nace como una unidad de información analógica, será sometido posteriormente a un proceso de conversión al campo digital y es también una actividad de formalización estructurante del conocimiento, que necesita de un diseño conceptual. Podemos decir que el proceso de datificación consta de tres etapas que serán definitorias respecto del corpus documental:

1. Conocer y reconocer las capacidades y cualidades relacionales del corpus documental.

2. Definir el o los métodos apropiados para el acopio de datos.

3. Elegir las herramientas adecuadas para el manejo y la interpretación de los datos.

Determinar la capacidad y las cualidades del corpus habilita al investigador a entender el andamiaje relacional que puede construirse con los datos (como formas de conceptualización, consistentes y regulares), que configuran, en sí mismos, un sistema. De esa consistencia y regularidad se identificarán diversos patrones relacionales que conformarán distintos racimos de nodos (clusters), agrupados en virtud de diversas relaciones posibles de ser cuantificadas.

Al tratarse del estudio de revistas, consideramos como nodos a actores individuales o grupales (el equipo editorial, el consejo directivo), pero también a secciones o números de la revista. Asimismo, consideramos a las aristas como trazas que registran todo tipo de relaciones vinculares, por ejemplo, los intercambios de capital en el espacio dado, pudiendo ser éste variado y diverso. Utilizamos las herramientas de análisis de redes para la visualización del universo de la revista, las relaciones e interacciones de los distintos tipos de nodos entre sí, lo cual posibilita dimensionar de forma gráfica las intensidades y magnitudes de las relaciones. Con la datificación se organiza una forma de evidenciar aquello que es inherente a la inmaterialidad de ciertos objetos: la datificación procura encontrar regularidades, principios de organización y clasificación que generan nuevos significados. Construir el dato es ya, en sí mismo, un acto de significación; hacerlo funcionar en un corpus de datos permite generar nuevas significaciones. Lemercier y Zalc ${ }^{35}$ proponen dos instancias para empezar a trabajar con

35 Lemercier y Zalc, Quantitative methods in the humanities, p. 51. 
datos: la primera es el ingreso de éstos, etapa a la que denominan "input", que es la conversión de los datos de un documento en un archivo digital, y una segunda instancia a la que llaman categorización, en que las entradas son clasificadas en categorías lo más homogéneas posibles, que luego pueden ser procesadas numéricamente.

Partiendo de que una red social es una estructura relacionada de patrones regulares, no lineales, es de suma importancia conocer a fondo las estructuras subyacentes de la revista, ya que eso permite delinear las diversas estrategias a seguir para el acopio de datos. En esta investigación hemos optado por realizar una base de datos en la que cada registro consta de 100 campos que abarcan todos los aspectos que se consideró necesario datificar; luego, en la carga, se verificó que no era posible cumplir, para cada registro (casi dos mil, sin contar la sección Bibliografía), el llenado de todos los campos (por ejemplo, otros autores mencionados en las reseñas bibliográficas).

Para completar estos campos, en primer lugar, hubo que tomar decisiones de normalización, relativas a nombres propios (autores, ciudades), fechas, datos numéricos, etcétera. Un registro mal establecido impide obtener información de calidad, tampoco puede cuantificarse ni graficarse, por incompleto o equívoco. Por ejemplo, aparecen tanto Fermín Peraza y Sarausa como Fermín Peraza Sarausa, así que fue necesario normalizar el dato. Lo mismo sucedió con mujeres que firmaron con su apellido de soltera y con su apellido de casada. En la mayor parte de los casos se pudo encontrar el nombre correcto, pero algunos casos se decidieron arbitrariamente.

Con respecto a ciudades, fue importante establecer fehacientemente de cuál se trata, si lo que se busca es generar representaciones de la circulación de capitales (cualesquiera sea el tipo) con mapas o grafos georreferenciados. Un ejemplo es el caso de Cuenca, nombre de una ciudad española y de una ciudad ecuatoriana, por tanto, fue necesario determinar con claridad a cuál se hace referencia para posteriormente cuantificar y georreferenciar adecuadamente las cantidades de reseñas. Tras ese paso sigue una etapa de integración. Las hojas de cálculo y las bases de datos entregan información según se organiza la demanda, lo que permite hacer múltiples y diversos cruces con la aplicación de distintos filtros. El momento de la integración implica sumar, combinando, los datos cargados en la base: cantidad de artículos, de reseñas, de menciones de revistas; cantidad de autores por número, por sección; ciudades de edición de libros y revistas, entre una vasta posibilidad de combinaciones de registros. Esta etapa no se confunde con restituir y reordenar la información al origen, sino que es cruzar, combinar, clasificar, cuantificar y producir otra información con ella. De esta tarea se generan resultados cuyas representaciones gráficas permiten ver el mismo objeto de formas diversas, como mapas, grafos, diagramas de barras, aluviales o tipo 
pirámide, y nos dan una nueva perspectiva de la información: los gráficos se convierten así en una herramienta heurística.

La base de datos dedicada a analizar el corpus de la RHA consta de más de 1900 registros que identifican páginas iniciales y finales (institucionales y publicitarias), artículos, reseñas, revistas, bibliografía, necrológicas y noticias. Como ya se indicó, la sección Revistas llegó al número 10, y luego se unificó con Bibliografía. Esta magnitud de información significó otro tratamiento, dado que, de registrar cada libro o revista como una ficha de la base de datos, habría sumado más de 16000 registros con un mínimo de siete campos (alrededor de 112000 campos registrados). ${ }^{36}$

Esta enorme cantidad de datos representaba un reto más que inalcanzable si se aplicaba a esa sección la misma metodología empleada en las otras secciones de la revista. Si bien en el ámbito de las humanidades digitales, ${ }^{37}$ específicamente aquellas acostumbradas al manejo de big data, estas cantidades pueden parecer insignificantes, en parte porque la forma de obtener los datos en esas áreas se realiza mayormente dentro de lo que es el campo digital y por lo tanto no hay "pérdida" de datos al momento de su captura, ${ }^{38}$ en esta investigación se afrontó el reto de convivir en un mundo híbrido, en el que la conversión análogo/digital siempre produce mermas que retrasan la elaboración correcta del trabajo. Se tomaron decisiones de manera creativa sobre cómo reducir los tiempos de obtención, proceso y análisis de los datos. $^{39}$

Se optó por no realizar una base de datos para esta sección y se trató de $e^{e m u l a r^{40}}$ la forma de trabajo que por lo general se realiza en humanidades digitales, es decir, ya que el punto débil en esta etapa era la conversión aná-

36 Con esta sección, se procedió a realizar una captura y refinamiento de los datos a gran escala, para posteriormente ordenar la información antes de exportarla para realizar gráficos de redes.

37 Sobre las humanidades digitales como un nuevo campo interdisciplinario que integra las tecnologías de cómputo a las humanidades, véase a Galina, “¿Qué son las Humanidades Digitales?”.

38 Aquello que Lemercier y Zalc denominan “dirty datasets”.

39 Un cálculo rápido indica que, para llenar los siete campos de la hipotética base de datos, un asistente tardaría unos 8 minutos, multiplicado por 16000 registros (aproximadamente), lo que da un total de más de 2100 horas de trabajo.

40 Muchos de los trabajos realizados bajo el ala de lo que se llama humanidades digitales toman sus fuentes para investigar de bases de datos que están publicadas en línea; en otros casos acceden a trabajos en los que las fuentes ya están digitalizadas, por lo que es nula la pérdida de datos al no existir la conversión análogo/digital.

Cuando hablamos de emular, hacemos referencia a imitar las acciones que realizan en el ámbito de las humanidades digitales procurando igualarlas; la emulación es aquella cualidad que permite a ciertas máquinas funcionar como otras, haciéndolas compatibles. 
logo/digital de la información, encontramos la forma de trabajar directamente en el campo digital.

La revista se encuentra en dos repositorios en internet: una en la Escuela Nacional de Antropología e Historia (ENAH), en la que están escaneados los números del primer decenio, y otro era el de JStor. Con el de la ENAH fue imposible trabajar, ya que están escaneados a muy baja resolución, y los de JStor estaban a la resolución correcta para poder convertirlos a texto mediante un OCR (un software de reconocimiento óptico de caracteres). El siguiente paso fue “arrobar” (se eligió el carácter @ porque no había sido utilizado en ninguna parte del texto) los datos de los campos requeridos; luego, con el programa Open Refine se "cargó" el texto y se seleccionaron las partes que estaban arrobadas, desechando todo lo demás. ${ }^{41}$ Se exportaron esos datos como archivos CSV y en Excel se realizaron los ordenamientos necesarios para trabajarlos en Gephi. ${ }^{42}$

A estas dos formas de capturar y ordenar la información proveniente de la sección Bibliografía de la revista se sumaron otras destinadas a recabar la rica y valiosa documentación primaria que, procedente de otros archivos externos, permiten explicar los resultados plasmados en la publicación y la estructura de las relaciones entre sus miembros. En este sentido, la correspondencia entre Silvio Zavala y numerosos colaboradores de la publicación fue fundamental para entender lo que en la práctica significaba fundar y lanzar número tras número. De igual manera, la correspondencia mantenida por Rafael Heliodoro Valle, encargado de la sección bibliográfica hasta 1941, permitió entender no sólo la importancia de esta sección, sino también la compleja red que se debió establecer para alimentarla. ${ }^{43}$

\section{ALGUNOS RESULTADOS VISUALES}

Una vez elaborada la base de datos proveniente de la información de la $R H A$ (por secciones como ya hemos comentado), se comenzó el requerimiento de

41 Esta decisión de desechar contrasta con lo que sugieren Lemercier y Zalc, ya que ellas indican la necesidad de que en esta etapa de trabajo se complete el desmenuzado de todo el corpus documental por más que no se utilicen esos datos en este momento, pero debido a las premuras del caso sólo se datificaron los campos que eran de nuestro interés.

42 Bastian, Heymann, y Jacomy, “Gephi: an open source software for exploring and manipulating networks”.

43 El Fondo Silvio Zavala, resguardado por la Biblioteca Nacional de Antropología e Historia, es un rico conjunto documental del cual se revisó exclusivamente lo relativo a la revista en estos diez primeros años. La base de datos creada para tal fin registra más de 900 fichas. Los documentos de Rafael Heliodoro Valle se encuentran en el Fondo Reservado de la Hemeroteca Nacional. Dado que el número de cartas era manejable (200 documentos aproximadamente) no se realizó una base de datos. 
información, que permitió obtener unas primeras visualizaciones. Con ello no sólo se han realizado diferentes tipos de gráficos (grafos de red, diagramas aluviales, mapas, nube de palabras), que sirvieron como formas de representación de información. ${ }^{44}$ Para este artículo consideramos que lo más importante es explicar por qué se realizó tal o cual gráfico para mostrar la forma en que se abordó el procesamiento de los datos en su descomposición en unidades discretas de contenido. Mostramos algunos resultados visuales de esta tarea.

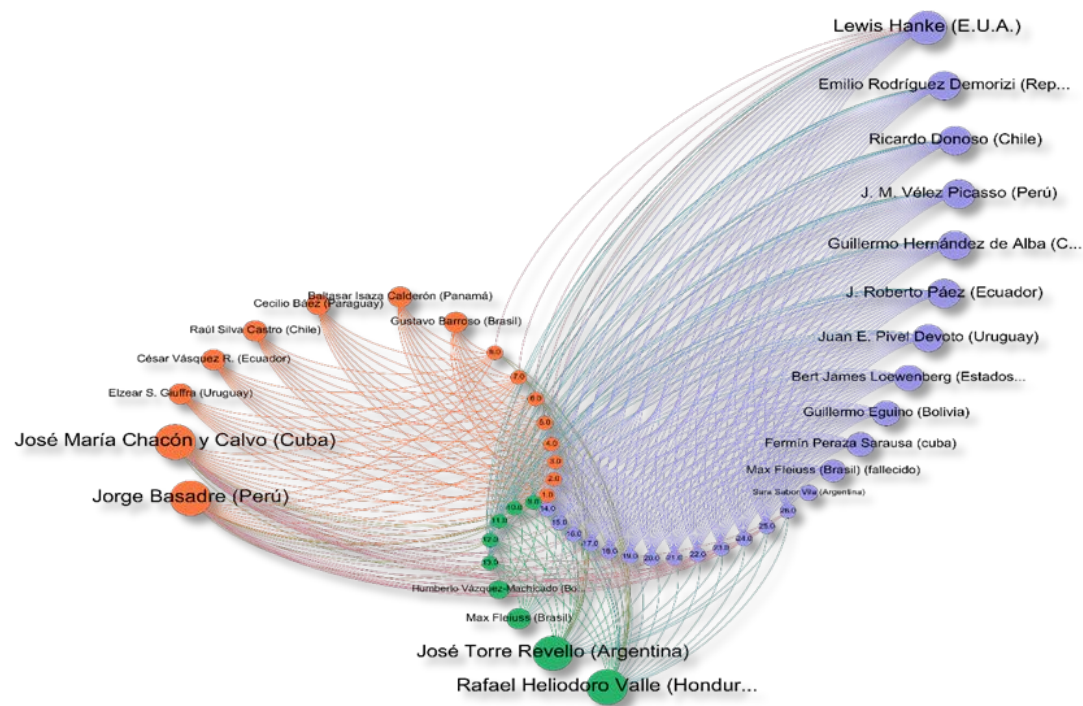

Gráfico 1. Grafo del Consejo Directivo. Representación de miembros por países en cada número, cálculo de modularidad de clase determina los colores, layout utilizado: radial axis ordenados por grado de salida. ${ }^{45}$

Como dijimos anteriormente, no hay una sola forma de ver las cosas, es decir, podemos tener los mismos datos con los mismos cálculos, con dos o más variaciones en las visualizaciones que podemos realizar, utilizando los

44 Estos gráficos sirvieron para explicar algún aspecto puntual en el libro sobre la revista que hemos mencionado en la introducción.

45 Todas las imágenes son de elaboración propia. Los grafos de red se hicieron utilizando Gephi. Mathieu Bastian, Sebastien Heymann, y Mathieu Jacomy. “Gephi: an open source software for exploring and manipulating networks”. International AAAI Conference on Weblogs and Social Media (2017). 
distintos tipos de software disponibles; por ejemplo, en el Gráfico 1, tenemos dos tipos de nodos: por un lado, están los números de las revistas analizados del 1 al 26, y por otro lado, tenemos a los miembros del Consejo Directivo. El primer análisis, y más sencillo, sería determinar quién estuvo en el Consejo en cuál número, lo cual nos permite inferir que hay dos grandes clusters, ${ }^{46}$ o grupos o racimos, sin la necesidad de ningún cálculo complejo, que se interconectan por medio de las participaciones. Ahora bien, cuando empezamos a realizar algunos cálculos, el grafo empieza a decirnos algunas cosas interesantes; primero al hacer el cálculo de modularidad de clase obtenemos tres comunidades identificadas de color lavanda, verde y naranja, y el tamaño de los nodos corresponde al grado de salida de cada uno de ellos, la distribución de los nodos se realizó con el layout radial axis ordenados por modularidad, en primer término, y por grado de salida, en segundo. Lo interesante en este grafo es ver cómo y en qué medida se relacionan las estructuras entre sí (son 9 estructuras detectadas a saber: lavanda, verde, naranja, lavanda + verde, lavanda + naranja, verde + lavanda, verde + naranja, naranja + lavanda, y naranja + verde), lo cual nos habla de que la relación entre los dos grandes clusters mencionados anteriormente es más compleja que la relación entre miembros del Consejo y los números en los que participan.

Un cuadro donde sólo se coloquen los nombres de los integrantes no nos daría la misma información porque en ella se pierde la dimensión temporal, como cuántos años participaron en el Consejo. Tampoco permitiría observar el peso que tuvieron (según su permanencia) en la revista. Como se muestra en el gráfico anterior, los nodos agrupados con el color morado son los que participaron en mayor cantidad de números, y la diferencia de grado entre ellos se debe a que algunos, como Lewis Hanke, tuvieron la mayor participación. Por supuesto que esta información aislada puede parecer demasiado sencilla, pero permite que el investigador empiece a dimensionar las personas que fueron fundamentales en la publicación. Esto nos llevó por ejemplo a observar la participación de Hanke como autor en la sección Artículos y Reseñas, pero sobre todo, llamó mucho la atención la correspondencia establecida entre el historiador estadounidense, el editor, el equipo editorial y otros colegas. A través de ese seguimiento nos percatamos de que su princi-

46 La definición que da GEPHI sobre el cálculo de clustering coefficient es la siguiente:

El coeficiente de agrupación es una medida del grado en que los nodos en un gráfico tienden a agruparse. La evidencia sugiere que en la mayoría de las redes del mundo real, y en particular las redes sociales, los nodos tienden a crear grupos muy unidos, caracterizados por una densidad relativamente alta de lazos; esta probabilidad tiende a ser mayor que la probabilidad promedio de un vínculo establecido aleatoriamente entre dos nodos. 
pal función fue la de ser un gran mediador en la red, al abrir y cerrar vínculos entre el mundo académico de su país y el de América Latina. ${ }^{47}$

Si bien esta estructura sencilla puede darnos pie a diversas interpretaciones acerca de la estructura relacional de estos nodos, si aplicamos el cálculo de la modularidad de clases, ${ }^{48}$ que también sirve para detectar comunidades, agrupamientos, racimos, etcétera, obtenemos la agrupación del Gráfico 2, donde distinguimos al igual que el grafo anterior tres comunidades.

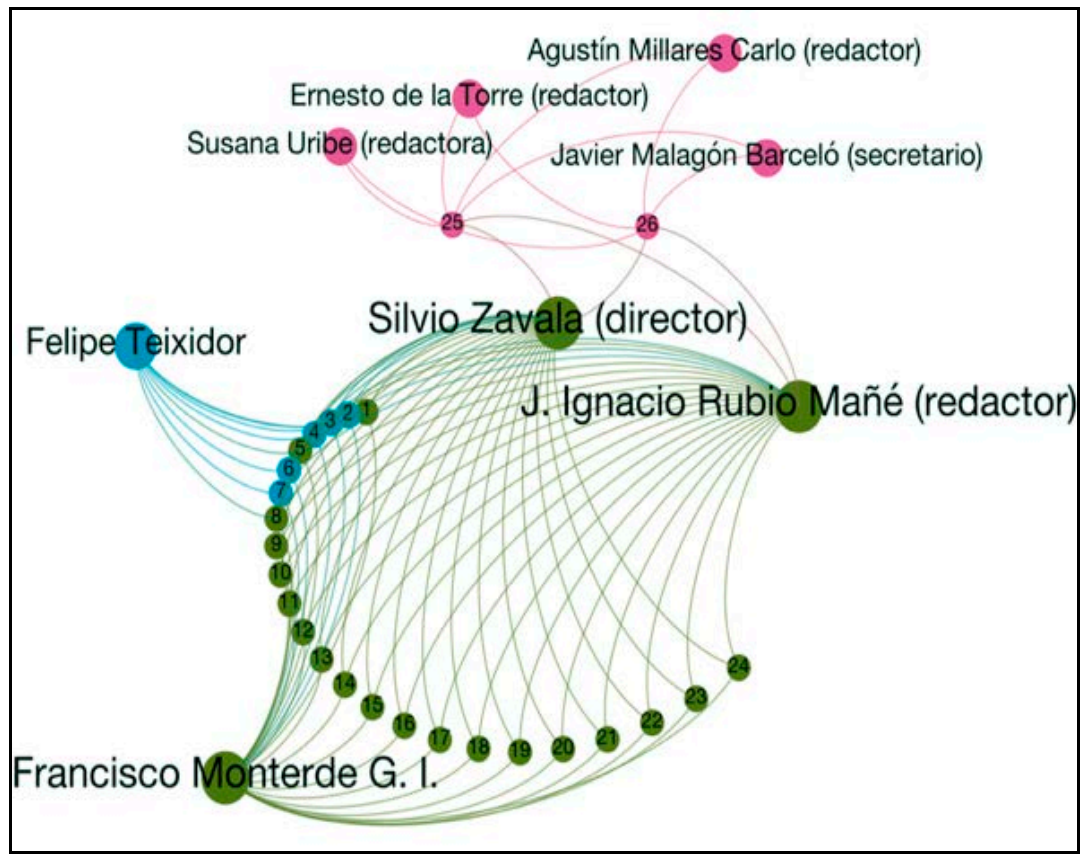

Gráfico 2. Grafo de editores por número, cálculo de modularity class, seis estructuras detectadas.

47 A través de la red de estos actores, circularían insumos que alimentarían la revista (canje de revistas, distribuidores, reseñas, artículos, notas bibliográficas, noticias, notas necrológicas).

48 La definición de modularidad de clases es:

una medida de la estructura de las redes, diseñada para medir la fuerza de la división de una red en módulos (también llamados grupos, grupos o comunidades). Las redes con alta modularidad tienen conexiones densas entre los nodos dentro de los módulos, pero escasas conexiones entre los nodos en diferentes módulos. La modularidad se utiliza a menudo en métodos de optimización para la detección de estructura de la comunidad en las redes. Kuz, Falco y Giandini, “Análisis de redes sociales: un caso práctico”, p. 94. 
En este caso, lo que se buscaba era identificar quiénes eran los miembros del equipo editorial que habían tenido mayor permanencia en el tiempo al haber participado en más números. Repetimos las observaciones anteriores, es decir, el gráfico permite identificar, no explicar, pero es una vía de entrada. Es evidente que Silvio Zavala y Jorge Ignacio Rubio Mañé ocuparon los lugares más relevantes, seguido por Francisco Monterde. Esta visualización nos permitió hacer nuevas preguntas para entender su función específica como miembros del equipo editorial y no sólo observar su permanencia. Para ello, nos remitimos al análisis de las secciones, detectando que los tres fueron autores de numerosas reseñas y notas bibliográficas (de artículos sólo Zavala se destaca). Eso nos llevó a buscar en otro tipo de documentación externa, como las cartas guardadas en el fondo Silvio Zavala, donde encontramos la información detallada, personal, sobre sus avatares en la participación.

Ahora bien, es conveniente utilizar distintas herramientas para diversificar el análisis de la dimensión humana y sus redes. Por ejemplo, los mapas ofrecen la posibilidad de geolocalizar la información, cuantificarla y desagregarla por ciudades, lo que fue de gran utilidad para analizar las reseñas de la RHA. Con esto nos dimos cuenta de que tanto los libros reseñados como las reseñas provienen principalmente de tres países: México, Argentina y Estados Unidos, lo cual permitió contrastar esta información con la de los archivos personales de correspondencias; identificar a las personas que hicieron posible esta sección, no necesariamente porque escribieran todas las reseñas, sino porque fungieron como mediadores para encontrar quienes lo hicieran: Silvio Zavala, Jorge Ignacio Rubio Mañé y Rafael Heliodoro Valle (desde México), José Torre Revello (Argentina) y Lewis Hanke (Estados Unidos).

Al afinar la búsqueda a escala ciudad, estos mapas muestran que, en el caso mexicano, por ejemplo, las reseñas (598) proceden exclusivamente de la Ciudad de México, situación similar a los otros países, donde había un predominio absoluto de las ciudades capitales. Esto nos permite hacernos preguntas que van más allá del análisis interno del texto para pensar en los circuitos de producción y circulación de los libros, pero también nos remite nuevamente a las redes intelectuales que hicieron posible la $R H A$. Sin estos vínculos personales es imposible entender por qué Cuba o República Dominicana tienen mayor peso que países más grandes (con más producción académica).

Otra forma de seguir refinando el uso de esta herramienta de geolocalización es la de buscar institucionalmente la procedencia de las reseñas, es decir, a partir de los autores que firman con una institución sus reseñas. Si nos centramos en el caso de las reseñas realizadas en la ciudad de México se 


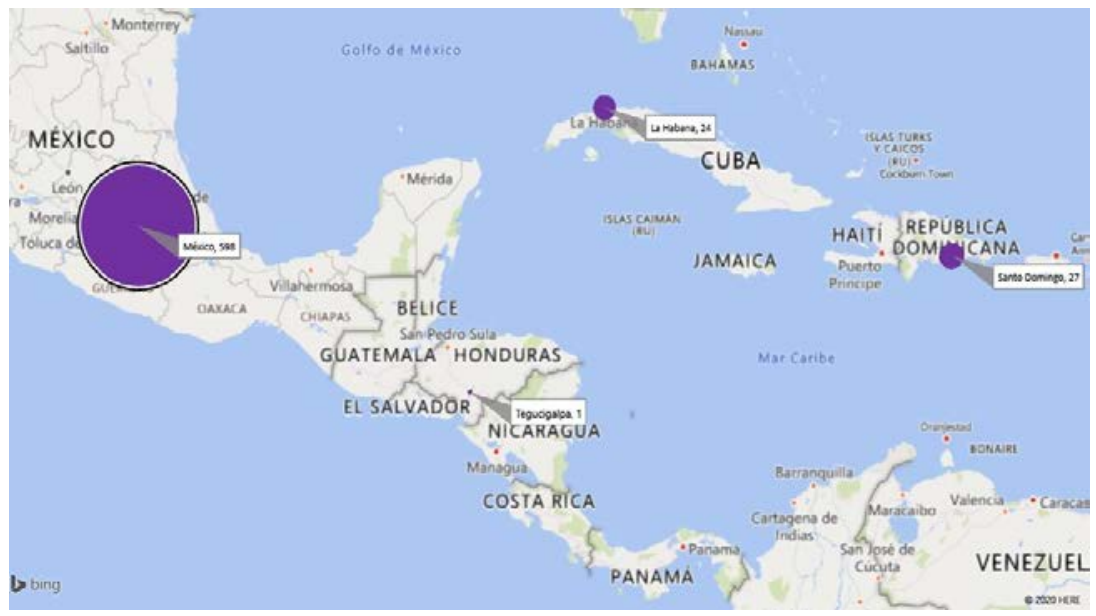

Gráfico 3. Mapa de Procedencia de los libros reseñados. ${ }^{49}$

puede observar el peso tanto del Centro de Estudios Históricos de El Colegio de México, como de la UNAM, a través de la Facultad de Filosofía y Letras y el Instituto de Investigaciones Históricas.

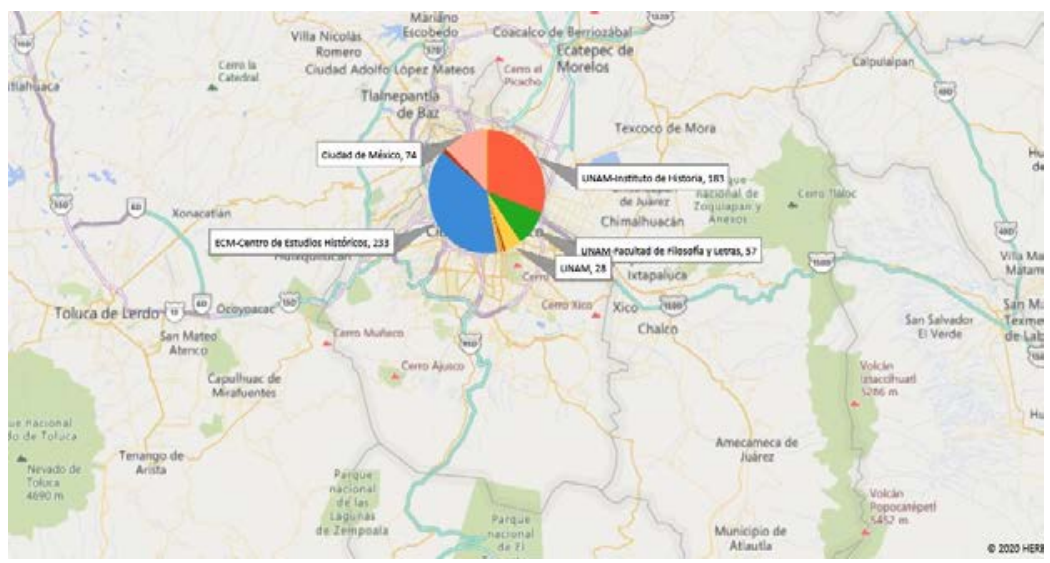

Gráfico 4. Mapa procedencia de los libros reseñados por institución referida.

49 Todos los mapas se generaron con la herramienta de Mapas 3D de Excel. Microsoft Office. Excel, 2016. 
Esto nos llevó a preguntarnos sobre la importancia que tenía la revista en la profesionalización de la historia en el país y, por otra parte, a la intrincada superposición de funciones que cumplieron sus colaboradores. Para el caso mexicano eso nos llevó a observar cómo simultáneamente Silvio Zavala fungió desde 1941 como editor, fundador del Centro de Estudios Históricos (poco después elegido director). Asimismo, permite entender mejor la relación de discipulado en las instituciones que propició la participación de jóvenes historiadores con sus reseñas, las primeras armas en publicaciones. Este fue el caso de Ernesto de la Torre Villar, quien participó como autor de numerosas reseñas y quien era estudiante de la primera generación de historiadores de dicho Centro.

Además, los títulos de los libros reseñados recibieron un tratamiento de cuantificación distinto, utilizándose en este caso el de contabilización de palabras, de lo que surge la siguiente visualización.
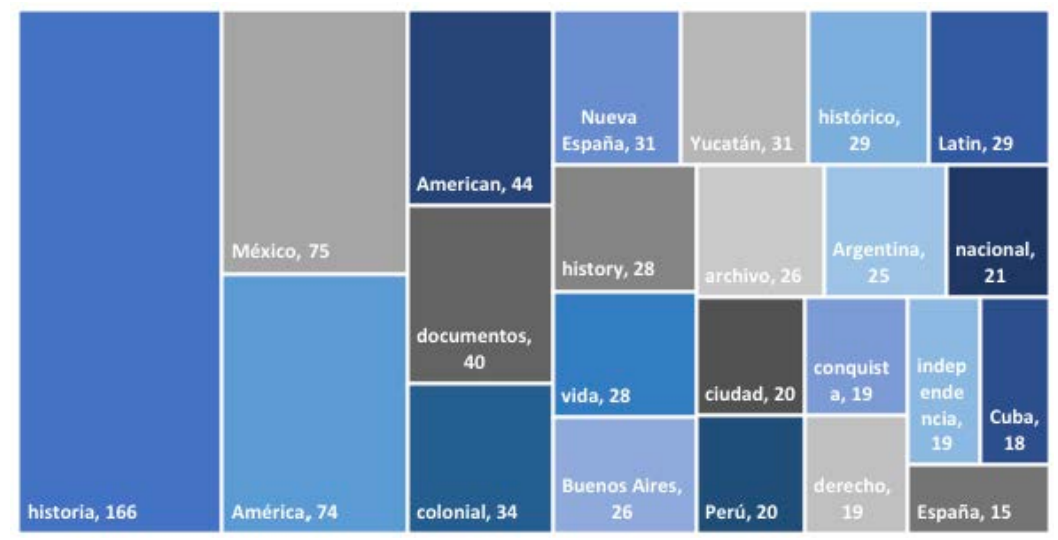

Gráfico 5. Palabras más repetidas en los títulos de los libros reseñados (primeros 26 resultados, de 3450 palabras relevadas).

Las herramientas cuantitativas aplicadas a los títulos de los artículos (84) permitieron identificar las palabras más repetidas. Esto nos remite a otro aspecto de lo inmaterial, a saber, los temas que ocuparon a los historiadores que colaboraron en la RHA. Si bien esto puede considerarse un detalle superfluo, no lo es. De inicio permite entender el proceso de selección que compartieron aquéllos que participaron en esta sección, lo cual implica preguntarse sobre las decisiones acordadas al interior de la red. Esto nos llevó nuevamente por dos caminos: uno, buscar internamente en otras secciones información que nos hiciera comprender qué sentido tenía el que aparecieran estas palabras como constantes, esto es, 
qué tipo de historia estaban de acuerdo en crear para representar el pasado del continente. Y dos, buscar correspondencia en fuentes externas, una explicación a cómo se tomaron estos acuerdos, cuáles eran las preocupaciones. Al reunir este cruce de variables y de nueva información pudimos comprender el verdadero sentido que tuvo para sus participantes el crear una revista dedicada a determinados estudios históricos con un rigor documental, cientificista, sobre la base de fuentes (y por tanto, la preponderancia de archivos y bibliotecas como centros documentales). Otro dato más nos brindaban las palabras asociadas a las referencias geográficas; la revista giraba entre América y España, lo que se confirma en la sección de artículos, con las palabras más repetidas (Gráfico 6).

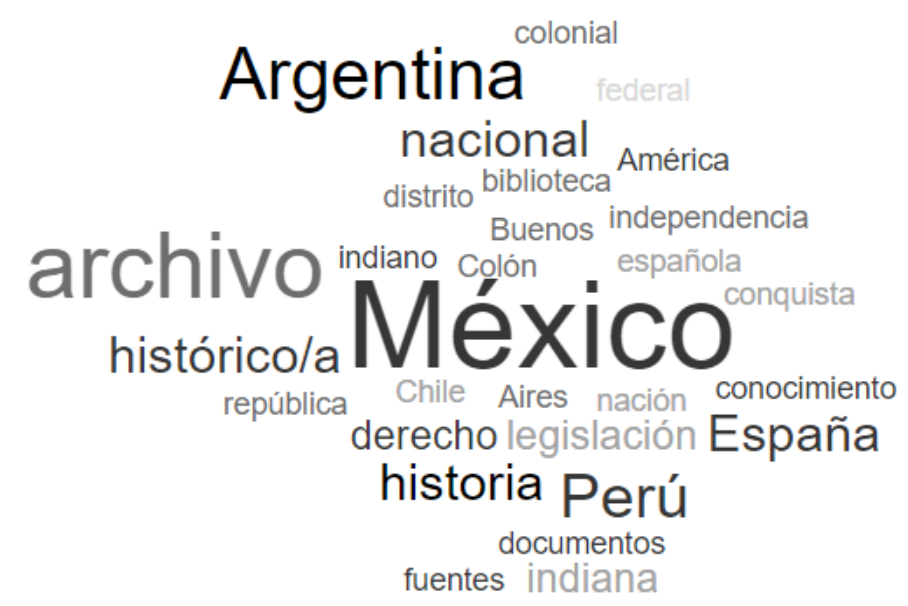

Gráfico 6. Palabras más repetidas en los títulos de los artículos. ${ }^{50}$

Esta representación corrobora la lectura de los títulos de los artículos y la identificación de sus palabras clave, con expresiones que remiten tanto a la historia colonial de América, con un peso acusado de México, como a las temáticas bibliográficas (artículos sobre bibliotecas y otros centros documentales). 
En la sección de Artículos se procedió igual que en la anterior sección, partiendo desde lo más simple hacia lo más complejo. Por eso, la siguiente visualización nos permite detectar a los autores que publicaron mayor número de artículos. La primera reflexión que surge es que se observa algo similar a lo que ocurre con las autorías de las reseñas: pocos autores publican muchos artículos, y una gran cantidad de ellos publica solo uno (Gráfico 7).

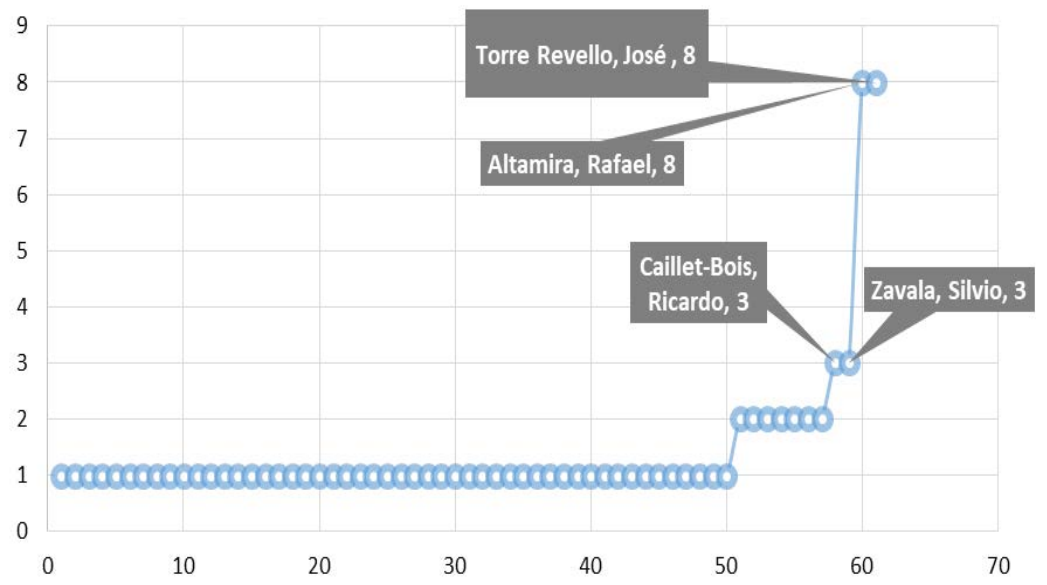

Gráfico 7. Cantidad de artículos producidos por los autores que publican más.

Además, nos permite observar que Zavala está en este grupo, pero no de una manera dominante, al publicar sólo tres artículos. En aquel período era frecuente que los directores publicaran de manera constante porque de algún modo representaban la voz cantante de la publicación. Sabemos que Zavala también publicó artículos en otras revistas durante esa época. En el caso de $R H A$, su presencia es mayor en las reseñas. Esto nos llevó a pensar en que el mexicano no planteaba su autoridad en la publicación en términos de centralidad en la autoría de artículos, que son las piezas de mayor extensión. Él estaba más enfocado en su función como editor y en el servicio que prestaba, por ejemplo, configurando, con sus reseñas, una biblioteca para el historiador. También nos lleva a reflexionar sobre el protagonismo de Rafael Altamira, su maestro en España, a quien después el exilio llevaría de nuevo a México, gracias a sus redes intelectuales. El caso de Torre Revello es distinto del de Altamira, porque su repetida aparición no se debe al prestigio académico, sino a su productividad.

Se hicieron varias visualizaciones de las secciones informativas: éstas son Noticias, a cargo de Ernesto de la Torre Villar, sección que empezó en 
junio de 1945, con el número 19,51 y Notas necrológicas, a cargo de diversos autores, a partir del número 8, en agosto de 1940, publicadas en diversos números, de forma irregular.

Es poco común que se realice un análisis de la sección Noticias de una revista. Su contenido suele ser abrumador, abarrotado de datos de instituciones, conferencias, congresos, reuniones, entre otros muchos temas posibles. En este caso no fue la excepción por lo que se decidió no utilizar gráficos de redes, sino otro tipo de visualización que permitiera capturar la vasta información de esta sección agrupándola por temas que detectamos como prioritarios.

Las noticias y otros documentos publicados en esa sección, como las actas de las reuniones, muestran la energía en el desarrollo de equipos y planes de trabajo, el despliegue continental y la visión de la necesidad de formación del historiador profesional. Desde la primera, en la que anuncian la sección, se fijan el objetivo de "promover una colaboración más estrecha entre los historiadores de América y a servir de medio de coordinación de la labor histórica en general”. ${ }^{52}$

A modo de ejemplo, se muestra una visualización de noticias relacionadas con el tema de archivo, que fue una temática constante en la RHA (Gráfico 8).

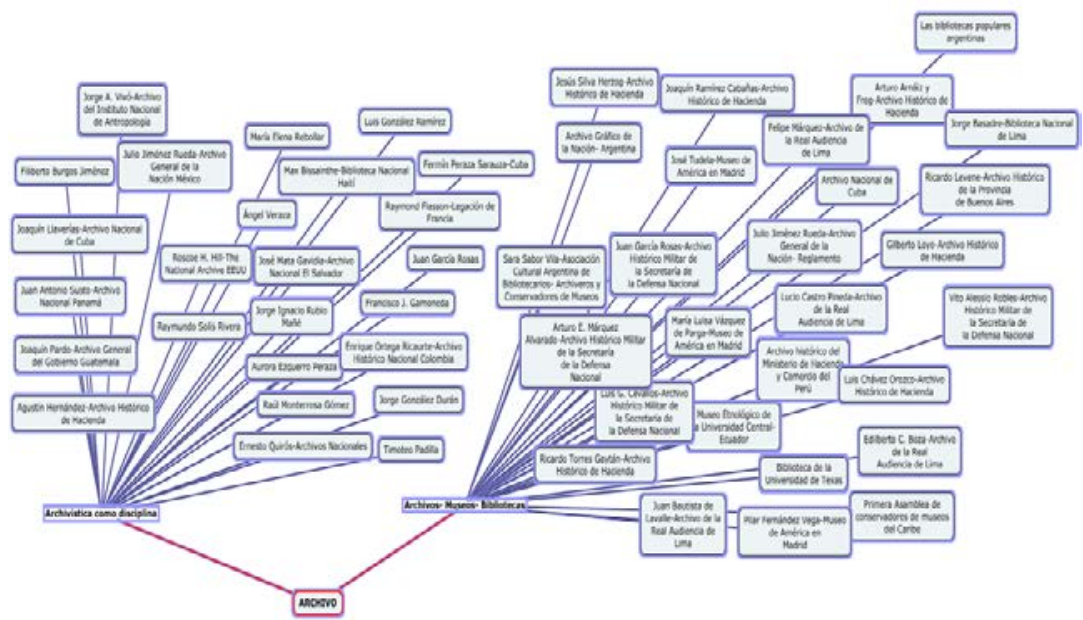

Gráfico 8. Personas e instituciones mencionadas en noticias relativas a la temática de archivo. ${ }^{53}$

51 Hubo en el número 11 una noticia referida a la II Asamblea General del Instituto Panamericano de Geografía e Historia.

52 Noticias, Revista de Historia de América 19, (1945), p. 131.

53 Gráfico elaborado con Cmap. IHMC. Cmaptools. Versión 6.04. 
En el caso de las notas necrológicas hemos realizado varios grafos de prueba porque el universo de datos que permite obtener esta sección es muy interesante. Por una parte, tenemos los datos del autor de la nota y en algunos casos, en las mismas notas se explica su relación con el fallecido (alumno, discípulo, colega); por la otra, tenemos la información del fallecido, nacionalidad, grado de estudios, instituciones formativas y laborales, revistas en las que participó y otros emprendimientos académicos, entre otros. Como vemos de estos gráficos podemos obtener algunos parámetros que nos pueden ayudar a entender la relevancia de este tipo de sección para el análisis de revistas culturales y, fundamentalmente, para comprender los lazos de filiación al interior de la red intelectual. En el primero de ellos, hemos realizado una catalogación entre formas y colores y podemos distinguir algunas cosas que están agrupadas de manera muy sencilla, distinguimos algunos agrupamientos producto de la detección de modularity class (homenajeados, autores de notas, citados e instituciones), junto con el cálculo de grado que define el tamaño de los nodos (Gráfico 9).

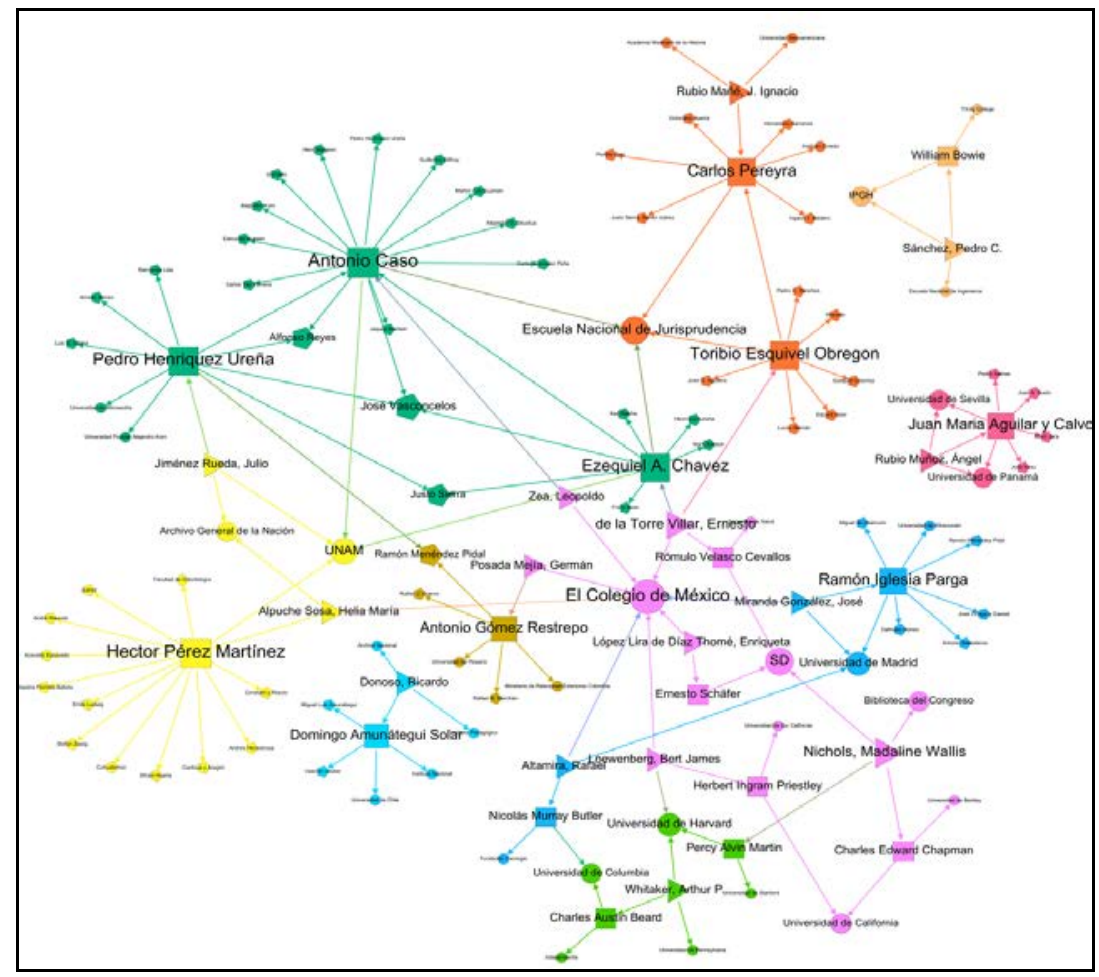

Gráfico 9. Grafo de necrológicas. Autores de notas, finados, citados, instituciones. 
En el Gráfico 10, son los mismos datos, pero se omitieron los de las instituciones, se detectaron comunidades por medio del cálculo de modularidad y el tamaño de los nodos en función del grado; es importante hacer notar la importancia de las instituciones en esta red, ya que son las que interconectan a la mayoría de los agrupamientos, El Colegio de México, la UNAM, y la Escuela Nacional de Jurisprudencia son los nodos que permiten una mayor cohesión de la red.

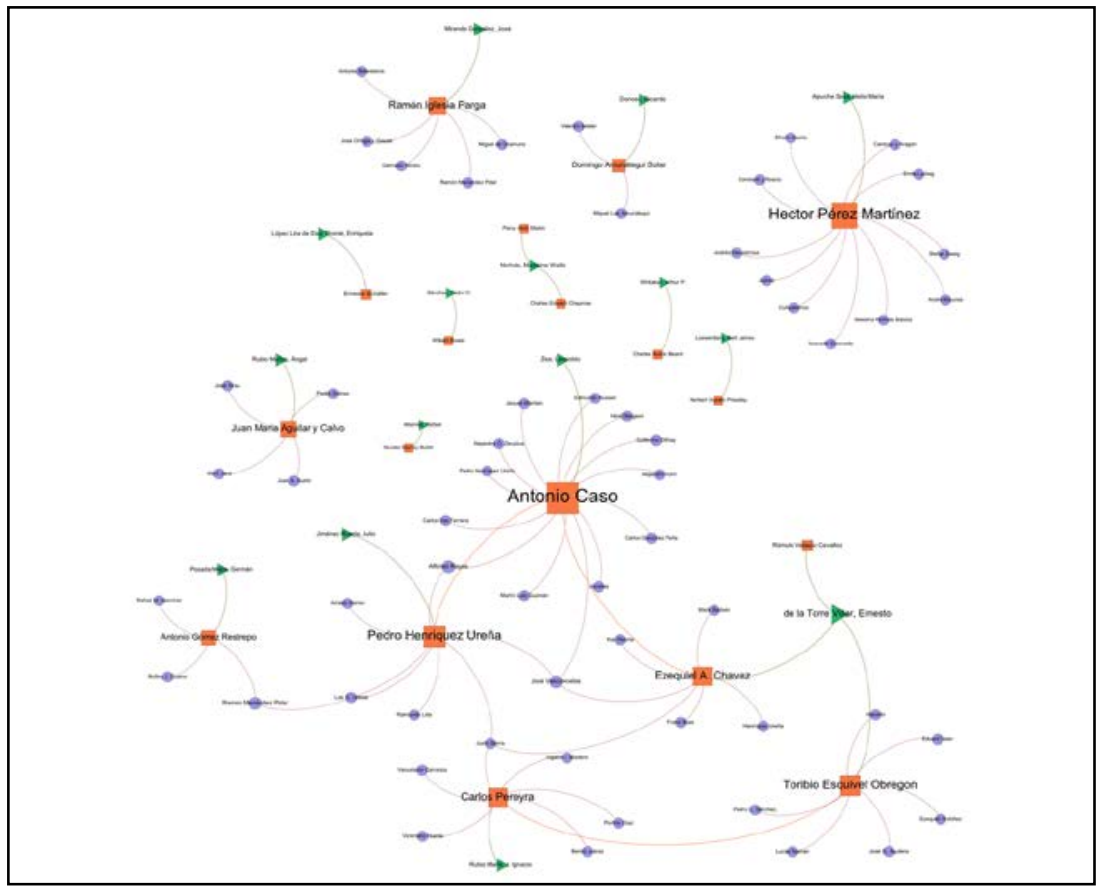

Gráfico 10. Grafo de necrológicas: detección de comunidades. Sin instituciones.

\section{CONCLUSIÓN}

Hemos estudiado el primer decenio de la revista en su heterogeneidad y también la hemos considerado como una textualidad que es capaz de representar relaciones entre sus miembros participantes. Como ya se indicó, también se abordaron cartas y otros documentos de circulación restringida (documentos privados o semipúblicos), que son otras textualidades en las que también se manifiestan las relaciones y que permiten ver la forma como se gestionaba el día a día de la revista. 
Así entendido, el análisis de redes es, más bien un análisis de las expresiones textuales de esas relaciones: sumadas al texto/textum/tejido (que es una red), las relaciones humanas componen un rico entramado que se expresa, imbricado al texto, y que es una forma de representación del conjunto de relaciones personales y profesionales que hizo posible la revista y su alcance continental, y la propuesta de un programa integral para el historiador, que suma docencia e investigación, con publicaciones diseñadas temáticamente para abarcar el continente.

En el caso de la $R H A$, los géneros son artículos, noticias, necrológicas, reseñas, bibliografías, notas de los editores y avisos publicitarios. Cada uno de ellos tiene su estilo y tema, su estructura, su forma de registrar la autoría, entre otros aspectos. Como señala el teórico literario ruso Mijaíl Bajtín, esta diversidad de los géneros discursivos está en estrecha relación con las actividades humanas, y con dimensiones ideológico-sociales: ${ }^{54}$ a cada género le corresponde una temática, una organización textual, un estilo.

Por ello es imprescindible no perder de vista las textualidades: hay una retórica, una forma de relación que se expresa discursivamente, que es constitutiva de los géneros, entendidos como una forma de expresión social e histórica particular. No es posible homogeneizar el género revista (en sí mismo heterogéneo y plural, hecho a base de textos diferentes, con distintas funciones y características) con los géneros más personales, como la correspondencia. Por poner un ejemplo muy elemental, no es igual la relación que establecen en la revista Silvio Zavala y colaboradores como Rafael Altamira (maestro de Zavala, exiliado español en México gracias a sus gestiones) o Lewis Hanke (con escasas contribuciones en $R H A$, pero un factor clave en la creación de la revista y en el vínculo con historiadores de Estados Unidos), que aquella que establecen estos mismos historiadores en la correspondencia personal. ${ }^{55}$ Según el género, la relación se expresa de un modo diverso. Es necesario prestar atención a esa diferencia que va de la revista como órgano institucional, formal, a documentos personales dirigidos de tú a tú. De manera que, a la hora de describir las relaciones, es necesario sumar a las representaciones gráficas una hermenéutica de los textos que les dan origen.

Somos conscientes de que todo esto implica un cambio significativo en nuestra manera de estudiar una revista porque no se suele trabajar con unidades mínimas discretas: estamos inmersos en narraciones, en grandes masas textuales de temas generales y particulares con objetos de todo tipo de

55 Sobre la diferencia entre autor real y figura textual del autor para la elaboración de redes sociales históricas, véase a Grillo en "Una red en el tiempo. el caso de La Campana de Palo, 1925-1927”, p. 152. 
escala, cruzadas también con otras series (política, económica, artística, literaria, intelectual). Desagregar va contra la habitual tendencia a leer e interpretar en masas de textos, en bloques más grandes, obliga a acercar el foco a datos pequeños que, en conjunto, son capaces de producir relaciones expresadas de manera visual y generar nueva información, entendiendo esa información como el producto de una relación. ${ }^{56}$

Sin embargo, como hemos mostrado, el corpus debe ser datificado y los datos deben ser construidos, es decir, identificados, tipificados en clases, enlazados a otros, integrados en hojas de cálculo y en bases de datos, para la cuantificación y para la reorganización posterior en nuevas unidades portadoras de nueva información, enriquecida y presentada visualmente. La información no es lo dado, es el producto de un hacer, y la forma como se ha procedido es eficaz para mostrar nuevas relaciones; al contenido de la revista leído (conocido, por tanto), se le suma el contenido expresado separada y organizadamente en categorías y campos, y es su recombinación la que produce un nuevo conocimiento. La integración ha sido el momento en que el contenido de la revista se ha configurado como un ítem o unidad de información. Creemos que este tipo de aproximación densa permite abordar el estudio de una revista de manera compleja. Como proceso, no se explica sólo a través de las acciones concretas involucradas en el procesamiento de la información (acciones como organizar, clasificar, ordenar, segmentar, reorganizar y graficar).

De esta manera, un objeto complejo (multidimensional), cambiante en el tiempo (dinámico), de múltiples autores, con variedad genérica, recibe un tratamiento complejo, que busca capturar datos en apariencia menores y producir información más rica, que da cuenta de mayor número de aspectos. Esto permite modificar significativamente nuestra manera de aproximarnos a una publicación: de una mirada preexistente que sobreestime el papel de su director y fundador (Silvio Zavala en este caso), a otra, de redes, en la cual sin perder de vista la importancia de los directores como nodos centrales, se pueda recomponer el papel destacado que cumplieron otros (miembros del equipo editorial, colaboradores, etcétera).

Cabe destacar que el ejercicio metodológico de la datificación nos llevó a descubrir nuevas formas de resolver el manejo de grandes cantidades de datos, minimizando de manera significativa la pérdida de ellos en el proceso de conversión análogo/digital. En cuanto a la elaboración de los grafos y todas las estrategias de visualización que se utilizaron, es conveniente aclarar que son meros auxiliares de la investigación; su propósito es materializar

56 Charaudeau y Mizraji, El discurso de la información: la construcción del espejo social, p. 44 . 
y comprender estructuras subyacentes en la trama que se teje al relacionar los datos, y que de otra manera sería imposible de explicitar. Incorporar al ámbito del estudio de las revistas herramientas hasta ahora utilizadas en otros campos, implica pensar nuevas formas de uso y nuevos conceptos (el de datificación). Asimismo, las redes graficadas nos llevan a plantear la necesidad de pensar los nodos en función de dar cuenta de todas las posibilidades de intercambio en una revista (no restringiendo su uso para representar sólo a los actores).

Queremos expresar una última reflexión. Leer y estudiar una revista antes de la era digital era una operación lineal y secuencial, desde su materialidad, abordando su contenido y las autorías. Sin embargo, la posibilidad actual de trabajar con grandes masas de contenido digitalizado y descompuesto en un universo de datos codificados con descriptores, almacenados en bases de datos y reintegrados en diversas herramientas visuales, permite recorrer una publicación en un sentido diverso, que se suma, sin cancelar, al anterior, para obtener una visión diferente, que permite identificar estructuras, patrones y relaciones que tal vez se escapan cuando la masa de contenido es abundante.

\section{SIGLAS}

HN- FHV Hemeroteca Nacional, Fondo Rafael Heliodoro Valle

BNHA, ASZ Biblioteca Nacional de Antropología e Historia-INAH, Acervo Silvio Zavala

\section{BiBLIOGRAFÍA}

Anthony, Laurence, AntConc, Waseda University, Japan, Faculty of Science and Engineering, 2014.

Bajtín, Mijaíl, "El problema de los géneros discursivos”, Estética de la creación verbal, México, Siglo Veintiuno Editores, 1989, pp. 248-293.

Beigel, Fernanda, "Las revistas culturales como documentos de la historia latinoamericana”, Utopía y Praxis Latinoamericana, vol. VIII, núm. 20, 2003, pp. 105115, https://produccioncientificaluz.org/index.php/utopia/article/view/26320 [consultado el 13 de abril de 2020].

Bastian, Mathieu, Heymann, Sebastien y Jacomy, Mathieu, "Gephi: an open source software for exploring and manipulating networks”, International AAAI Conference on Weblogs and Social Media, 2017.

Bourdieu, Pierre, "Le capital social”, Actes de la Recherche en Sciences Sociales, no. 31, enero de 1980, obtenido de https://www.persee.fr/issue/arss_03355322_1980_num_31_1, (consultado el 2 de marzo de 2020). 
Bushner, David y Mcalister, Lyle N, “An Interview with Lewis Hanke”, HAHR, vol. 68, núm. 4, 1988, pp. 653-674.

DOI: https://doi.org/10.1215/00182168-68.4.653

Charaudeau, Patrick y Mizraji, Margarita, El discurso de la información: la construcción del espejo social, Barcelona, Gedisa, 2003.

Delgado, Verónica, “Algunas cuestiones críticas y metodológicas en relación con el estudio de revistas”, en Delgado, Verónica, Mailhe, Alejandra y Rogers, Geraldine (coords.), Tramas impresas: Publicaciones periódicas argentinas (XIX y $x x$ ), La Plata, Universidad Nacional de la Plata, Facultad de Humanidades y Ciencias de la Educación, 2014, pp. 11-25.

Ehrlicher Hanno, "El estudio de revistas culturales en la era de las humanidades digitales. Reflexiones metodológicas para un debate”, en Delgado, Verónica; Mailhe, Alejandra y Rogers, Geraldine (coords.), Tramas impresas: Publicaciones periódicas argentinas (XIX Y XX), La Plata, Universidad Nacional de la Plata, Facultad de Humanidades y Ciencias de la Educación, 2014, pp. 26-45.

Enideo, Word It out, 2020.

Fernández Castro, Roberto, "Silvio Zavala y la historiografía americana: una vida de vínculos intelectuales”, Revista de Historia de América, núm. 155, 2018, pp. 33-55. DOI: https://doi.org/10.35424/rha.155.2018.287

Galina Russell, Isabel, “¿Qué son las Humanidades Digitales?”, Revista Digital Universitaria, vol. 12, núm. 7, 2011, http://www.revista.unam.mx/vol.12/num7/art68/index.html [consultado el 8 de abril de 2020].

Grillo, María del Carmen, "Una red en el tiempo. El caso de La Campana de Palo, 1925-1927”, en Alexandra Pita González (comp.), Redes intelectuales transnacionales en América Latina durante la entreguerra, México, Universidad de Colima, Miguel Ángel Porrúa, 2016, pp. 135-166.

Hanke, Lewis, y Vericat, Isabel, “Experiencias con Silvio Zavala, 1933-1949: algunos recuerdos al azar”, Historia Mexicana, vol. 38, núm. 4, 1989, pp. 601607.

Kuz, Antonieta; Falco, Mariana; Giandini, Roxana, “Análisis de redes sociales: un caso práctico”, Computación y Sistemas, vol. 20, núm. 1, 2016, pp. 89-106, DOI: https://doi.org/10.13053/cys-20-1-2321.

Lemercier, Claire y Zalc, Claire, Quantitative methods in the humanities: An introduction, University of Virginia Press, 2019.

DOI: https://doi.org/10.2307/j.ctvbqs963.

Louis, Annick, "Leer una revista literaria: autoría individual, autoría colectiva en las revistas argentinas de la década de 1920”, en Rose Corral, Anthony Stanton, James Valander (eds.), Laboratorios de lo nuevo. Revistas literarias y culturales de México, España y el Río de la Plata en la década de 1920, México, El Colegio de México, 2018, pp. 27-53. 
Louis Annick, "Las revistas literarias como objeto de estudio", en Hanno Ehrlicher y Nanette Risfler-Pipka (eds.), Almacenes de un tiempo en fuga. Revistas culturales en la modernidad hispánica, Aachen, Shaker Verlag, 2014, pp. 31-57. DOI: https://doi.org/10.2307/j.ctvckq2js.4.

Mauri, Michele; Tommaso, Elli; Caviglia, Giorgio; Uboldi Giorgio y Azzi, Matteo, "Rawgraphs: A Visualisation Platform to Create Open Outputs”, Proceedings of the 12th Biannual Conference on Italian SIGCHI, Nueva York, ACM, 2017: 28:1-28:5. DOI: https://doi.org/10.1145/3125571.3125585.

Mignolo, Walter, "El metatexto historiográfico y la historiografía indiana”, MLN, vol. 96, núm. 2, 1981, pp. 358-402. DOI: https://doi.org/10.2307/2906354.

Mora Muro, Jesús Iván, “Silvio Zavala y la institucionalización/profesionalización de la historia en México, 1933-1950”, Revista de Historia de América, núm. 155, 2018, pp. 57-89. DOI: https://doi.org/10.35424/rha.155.2018.288.

Pani, Erika, “Silvio Zavala y la historia de América: un juego de escalas”, Revista de Historia de América, núm. 155, pp. 177-189, 2018.

DOI: https://doi.org/10.35424/rha.155.2018.294.

Pita González, Alexandra y Grillo, María del Carmen, "Una propuesta de análisis para el estudio de revistas culturales”, Revista Latinoamericana de Metodología de las Ciencias Sociales, vol. 5, núm. 1, 2015, p. 30,

https://www.relmecs.fahce.unlp.edu.ar/article/view/relmecs_v05n01a06, [consultado el 17 de abril de 2020].

Pita González, Alexandra, "Las revistas culturales como soportes materiales, prácticas sociales y espacios de sociabilidad", en Hanno Ehrlicher y nanette Risfler-Pipka (eds.), Almacenes de un tiempo en fuga. Revistas culturales en la modernidad hispánica, Aachen: Shaker Verlag, 2014, pp. 227-246.

Pita González, Alexandra, “Introducción”, en Alexandra Pita (comp.), Redes intelectuales trasnacionales en América Latina durante la entreguerra, México, Miguel Ángel Porrúa, Universidad de Colima, 2016, pp. 5-24.

Pluet-Despatin, Jacqueline, “Une contribution a l'histoire des intellectuels: les revues”, Les Cahiers de L'IHTP, no. 20, marzo, Sociabilites intellectuels: lieux, milieux, reseaux, 1999.

Prada, Raúl, “Epistemología del dato”, Revista Mexicana de Sociología, vol. 49, núm. 1, 1987, pp. 307-334. DOI: https://doi.org/10.2307/3540436.

Rißler-Pipka, Nanette, “Sobre los problemas de investigación con revistas culturales digitalizadas del mundo hispanohablante”, en Hanno Ehrlicher y Nanette Risfler-Pipka (eds.), Almacenes de un tiempo en fuga. Revistas culturales en la modernidad hispánica, Aachen, Shaker Verlag, 2014, pp. 58-78.

Rodríguez Treviño, Julio César, "Cómo utilizar el Análisis de Redes Sociales para temas de historia”, Signos Históricos, vol. 15, núm. 29, 2013, pp. 102-141, https://signoshistoricos.izt.uam.mx/index.php/historicos/article/view/398/376 [consultado el 17 de abril de 2020[. 